\title{
One-Pot Synthesis of Benzimidazo[2,1-b]thiazoline Derivatives through an Addition/Cyclization/Oxidative Coupling Reaction
}

\author{
Haofeng Wang, ${ }^{\text {a\# }} \mathrm{Xin} \mathrm{Wu},{ }^{\text {a\# }}$ Luyu Wang, ${ }^{\text {a\# }}$ Erfei Li, ${ }^{\text {a }}$ Xiaoyu Li, ${ }^{\text {a }}$ Tao Tong, ${ }^{\text {a }}$ Honglan Kang, ${ }^{\mathrm{a}}$ \\ Jianwu Xie, ${ }^{\mathrm{a}}$ Guodong Shen ${ }^{\mathrm{b}}$ and Xin Lv*a
}

${ }^{a}$ Key Laboratory of the Ministry of Education for Advanced Catalysis Materials, College of Chemistry and Life Sciences, Zhejiang Normal University, Jinhua 321004, People's Republic of China.Email: lvxin@zjnu.cn

${ }^{b}$ School of Chemistry and Chemical Engineering, Shandong Provincial Key Laboratory of Chemical Energy Storage and Novel Cell Technology, Liaocheng University, Liaocheng 252059, Shandong, People's Republic of China.

\section{$\underline{\text { Table of Contents }}$}

1. Copies of ${ }^{1} \mathrm{H}$ and ${ }^{13} \mathrm{C}$ NMR Spectra for Products 3.....................S2-S25

2. Copies of ${ }^{1} \mathrm{H}$ and ${ }^{13} \mathrm{C}$ NMR Spectra for Intermediate 5a.......................S26

3. Copies of ${ }^{1} \mathrm{H}$ and ${ }^{13} \mathrm{C}$ NMR Spectra for Derivative 6a........................S27

4. Copies of ${ }^{1} \mathrm{H}$ and ${ }^{13} \mathrm{C}$ NMR Spectra for Derivatives 7................... S28-S30

5. Copies of ${ }^{1} \mathrm{H}$ and ${ }^{13} \mathrm{C}$ NMR Spectra for Derivative 8a..........................S31

6. The X-Ray Crystallographic Information of 3a.............................S32-S33 


\section{Copies of ${ }^{1} \mathrm{H}$ and ${ }^{13} \mathrm{C}$ NMR Spectra for Products 3.}

3a:

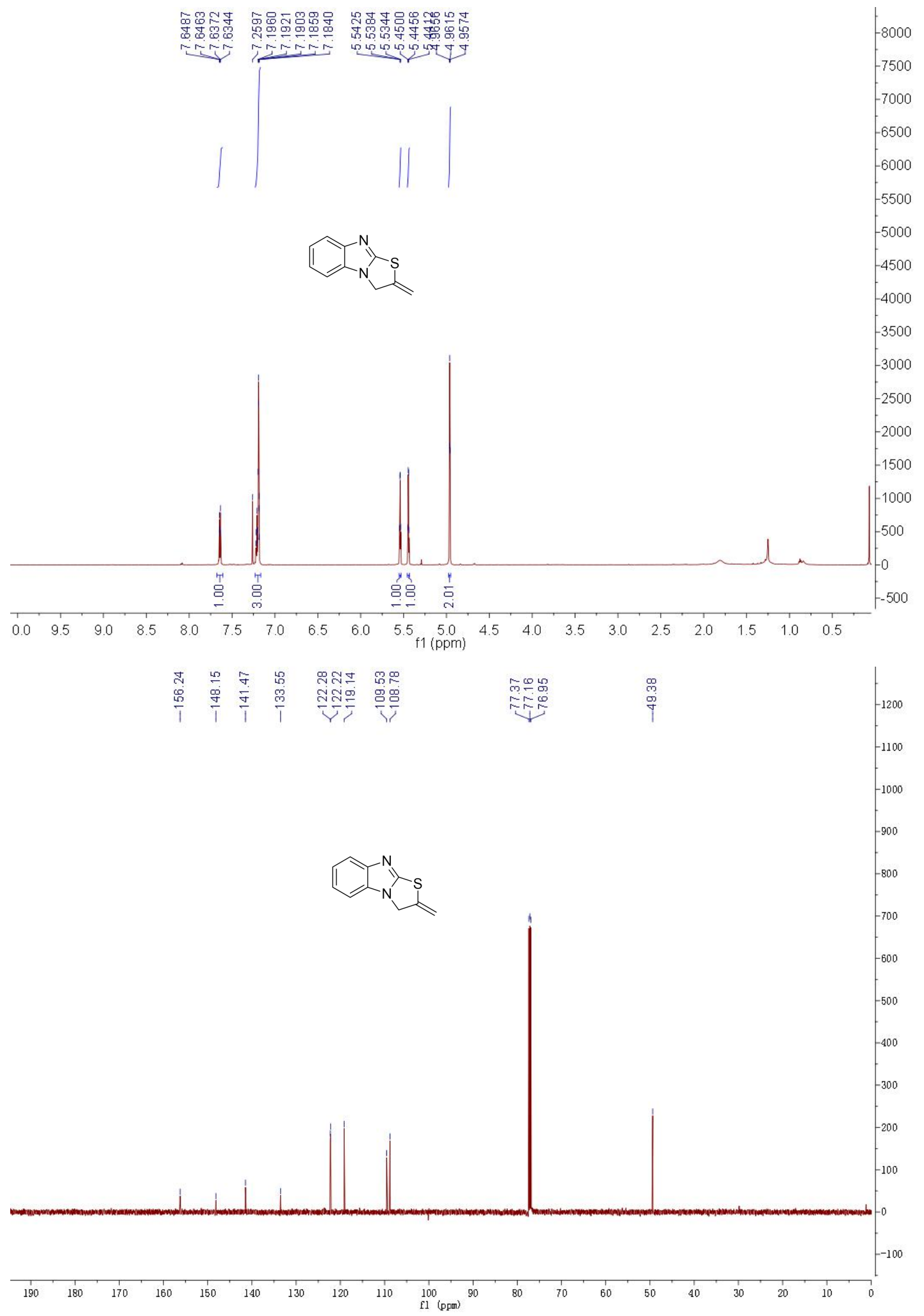


3b:
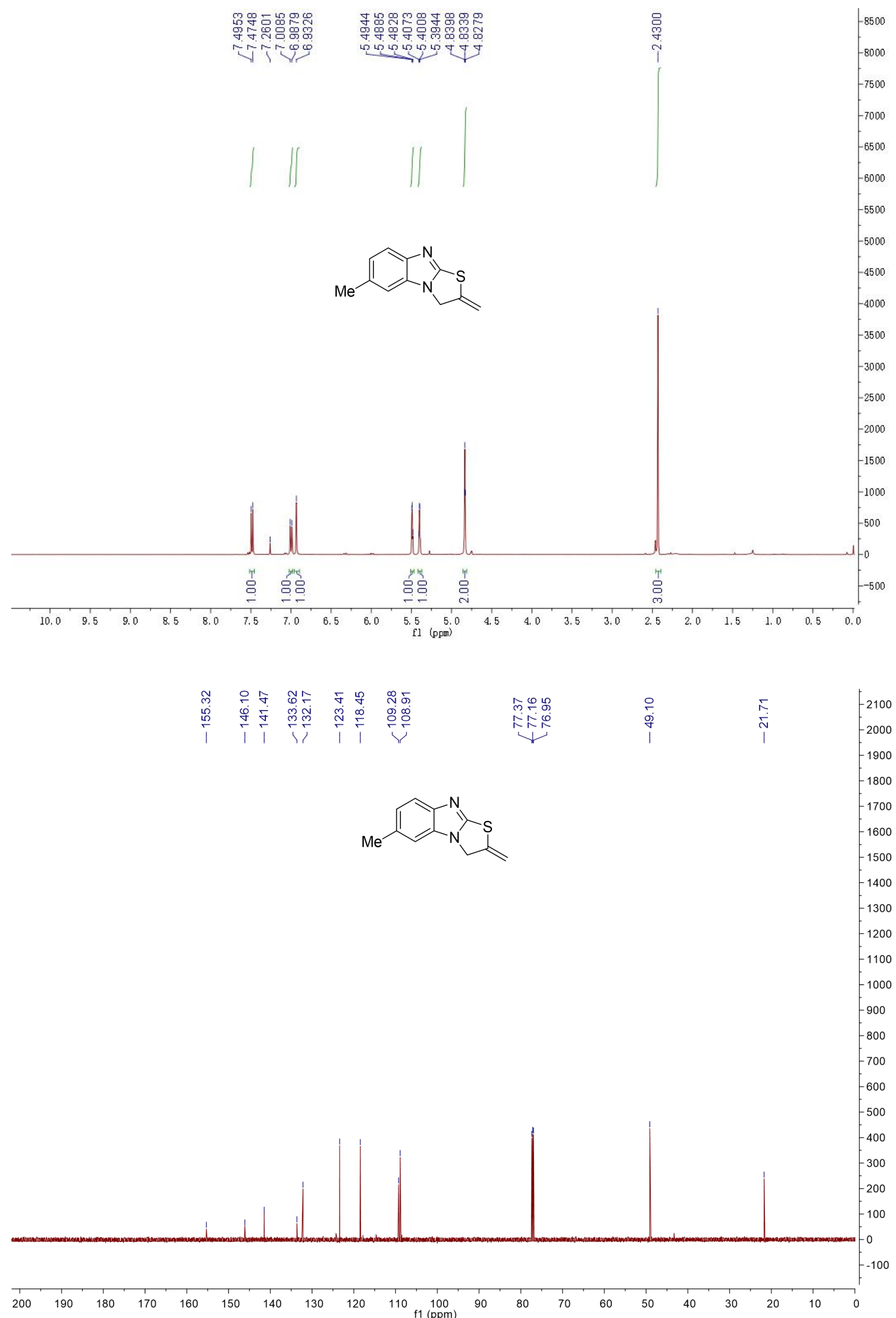
3c:

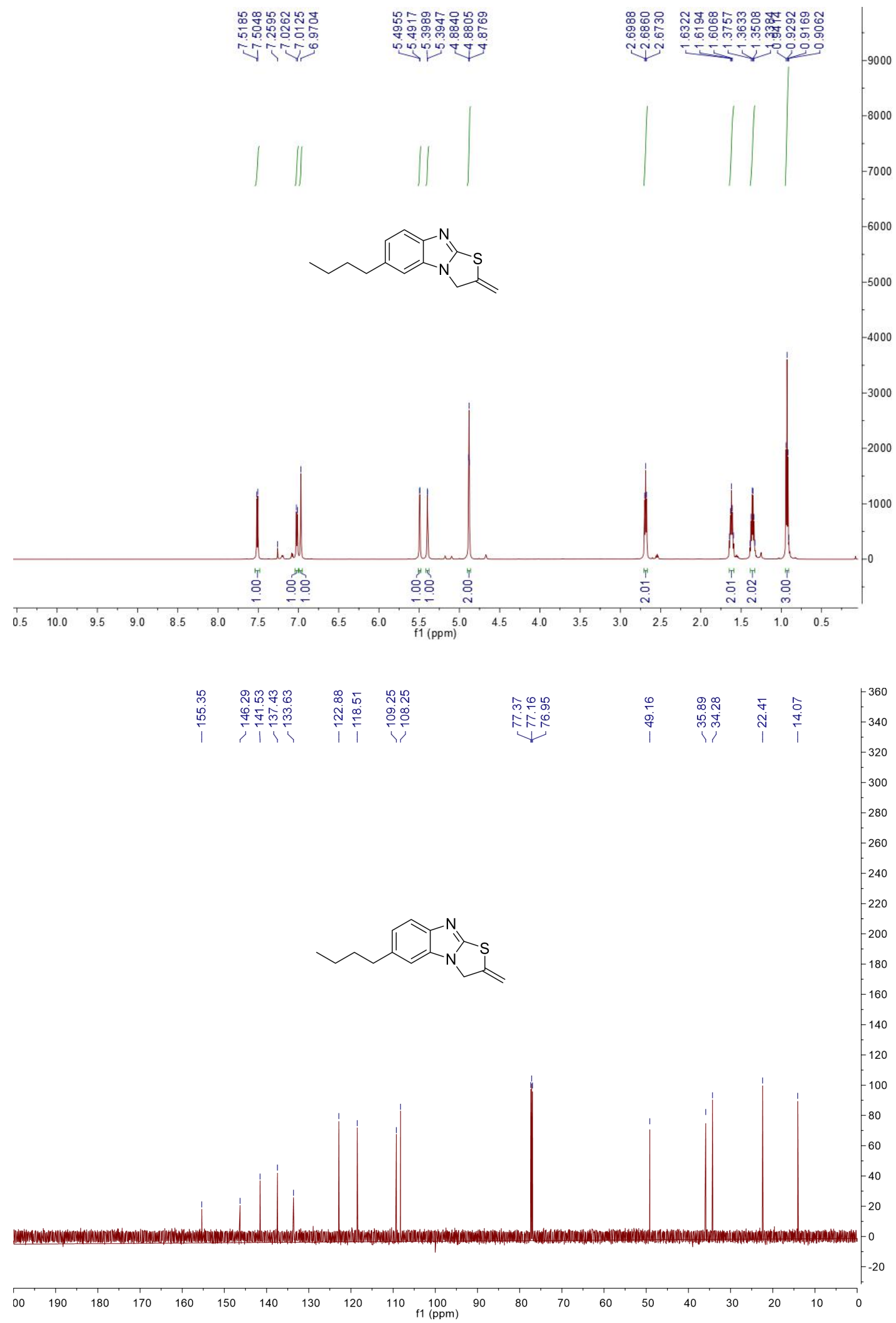


3d:
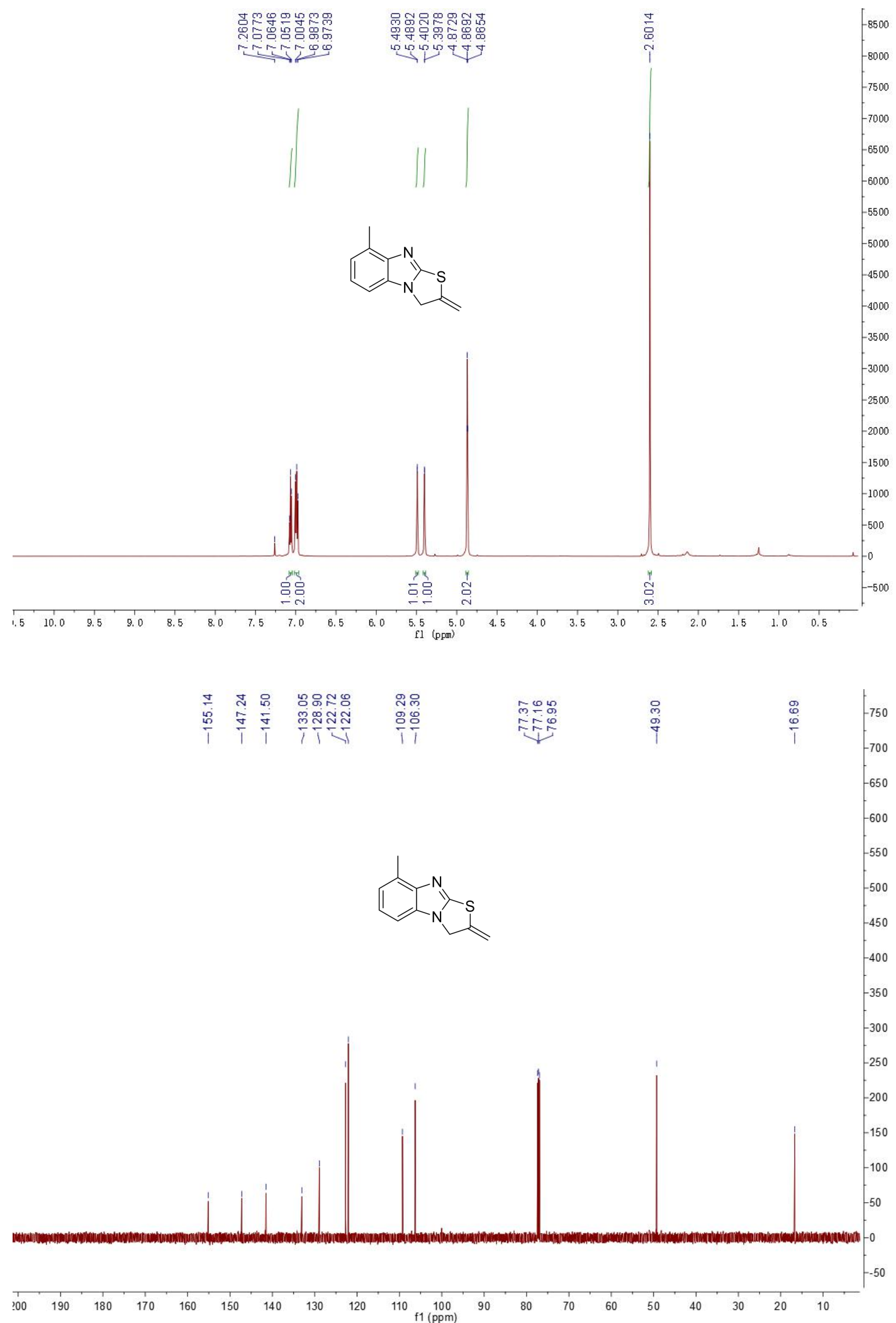
3e:

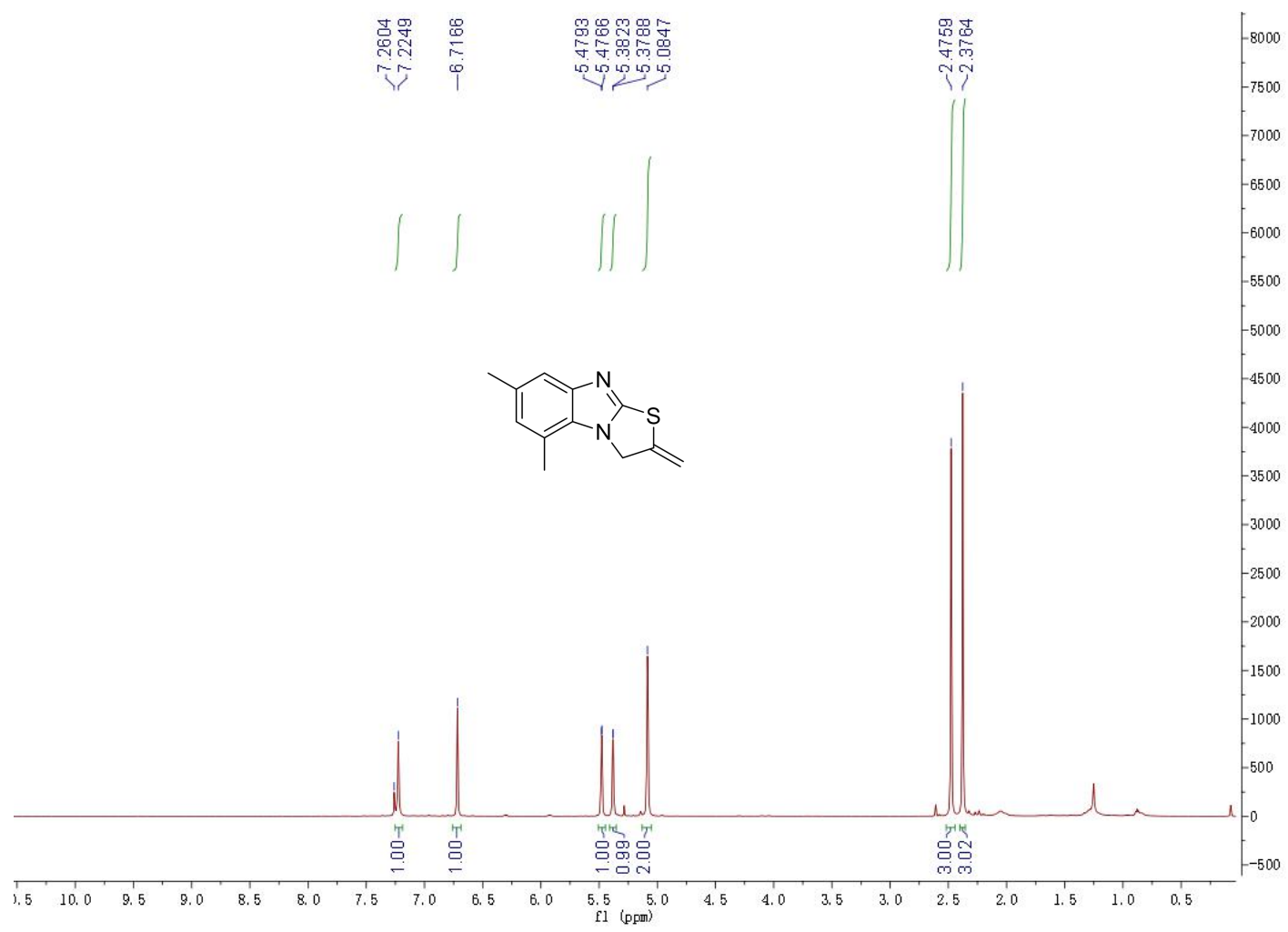

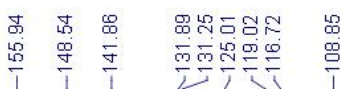

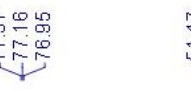

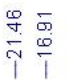

$-1100$

$-1000$

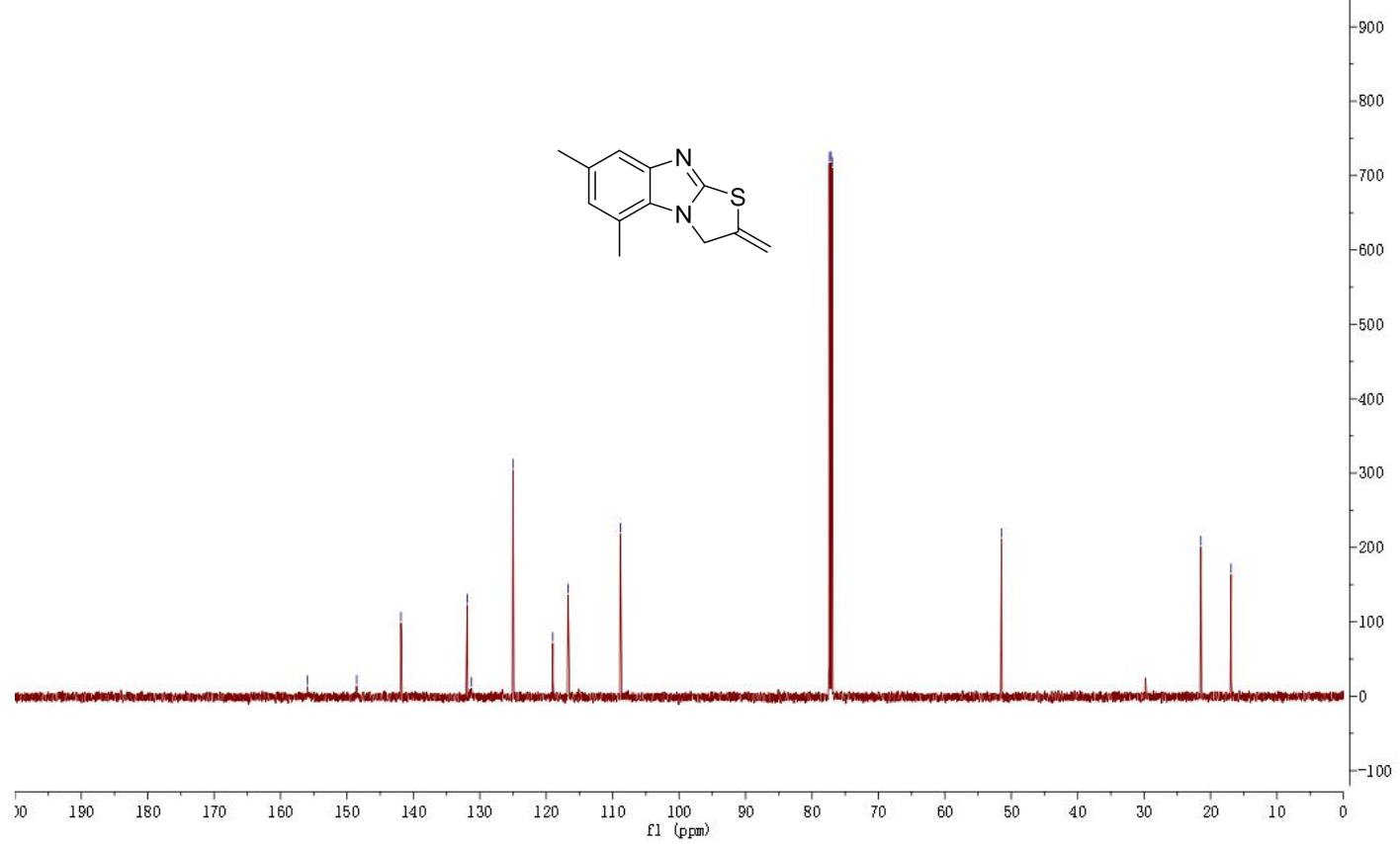


3f:

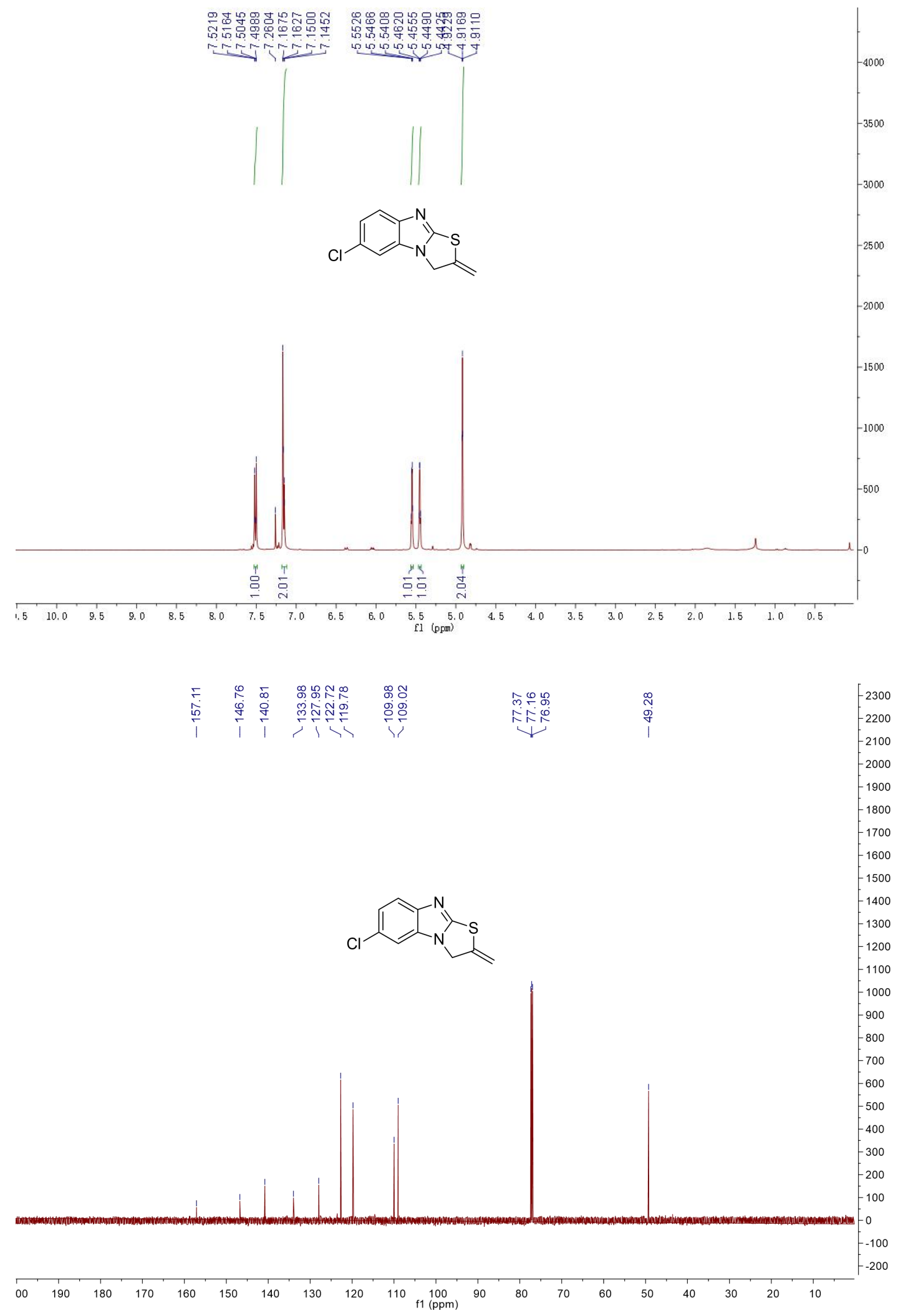


3g:
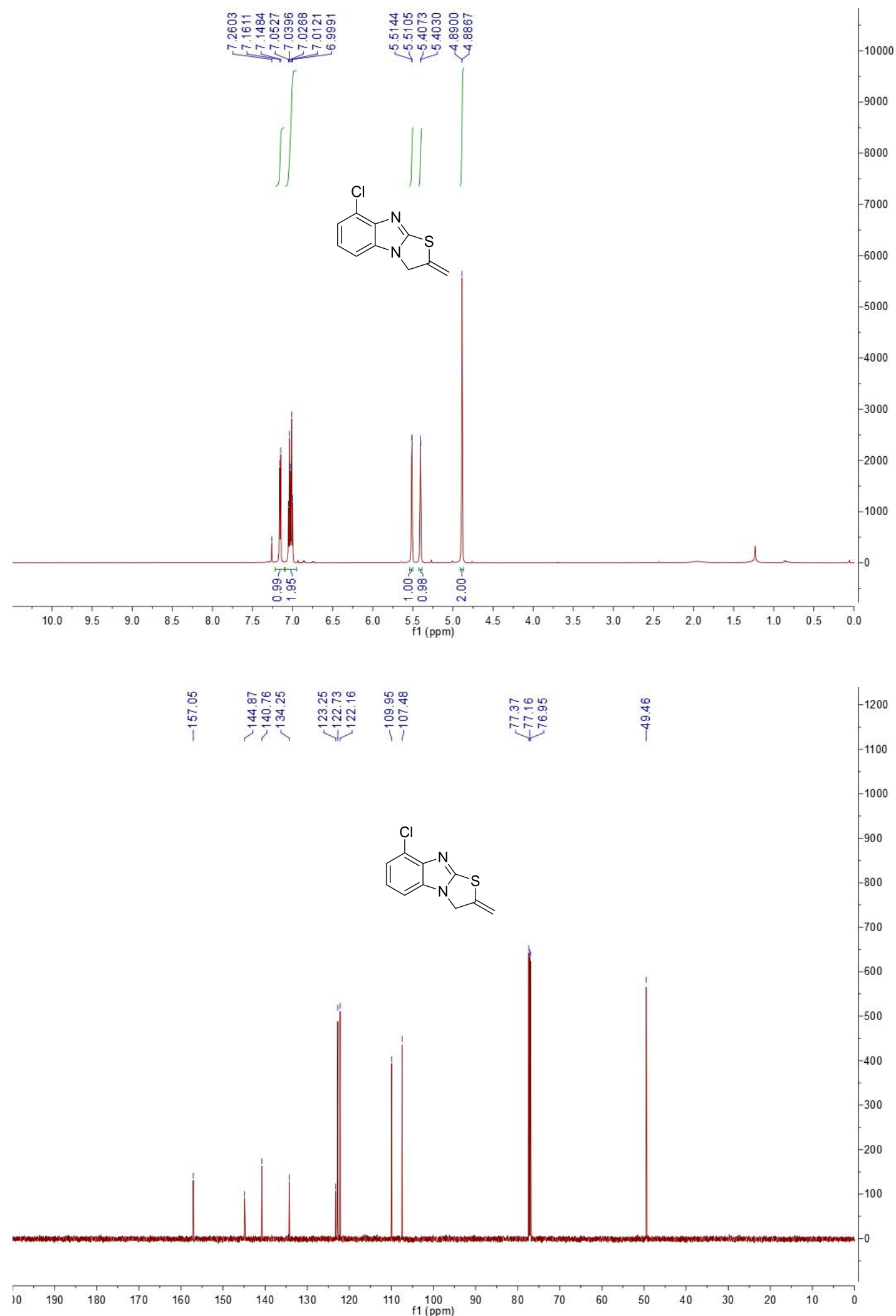
3h:
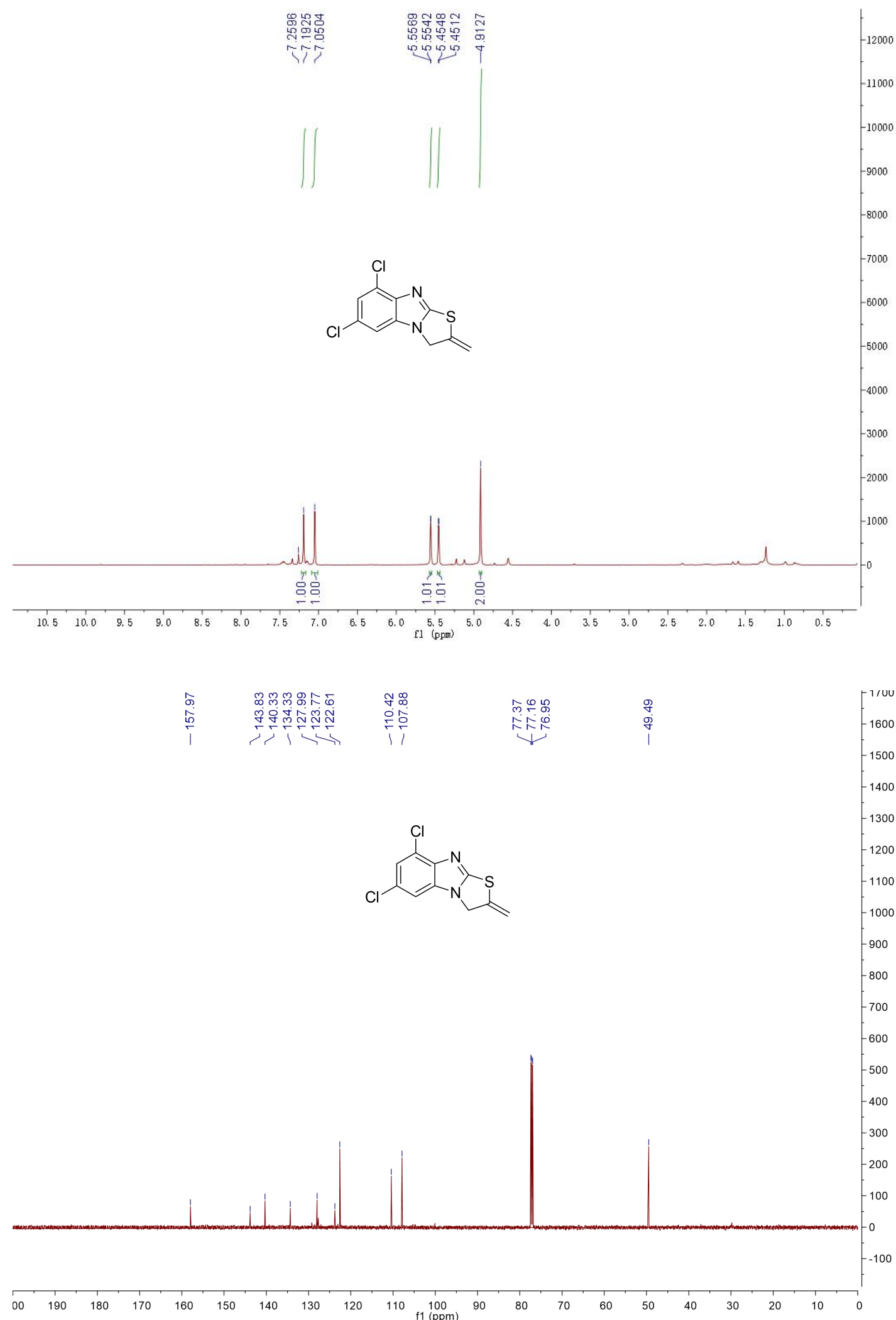
3i:

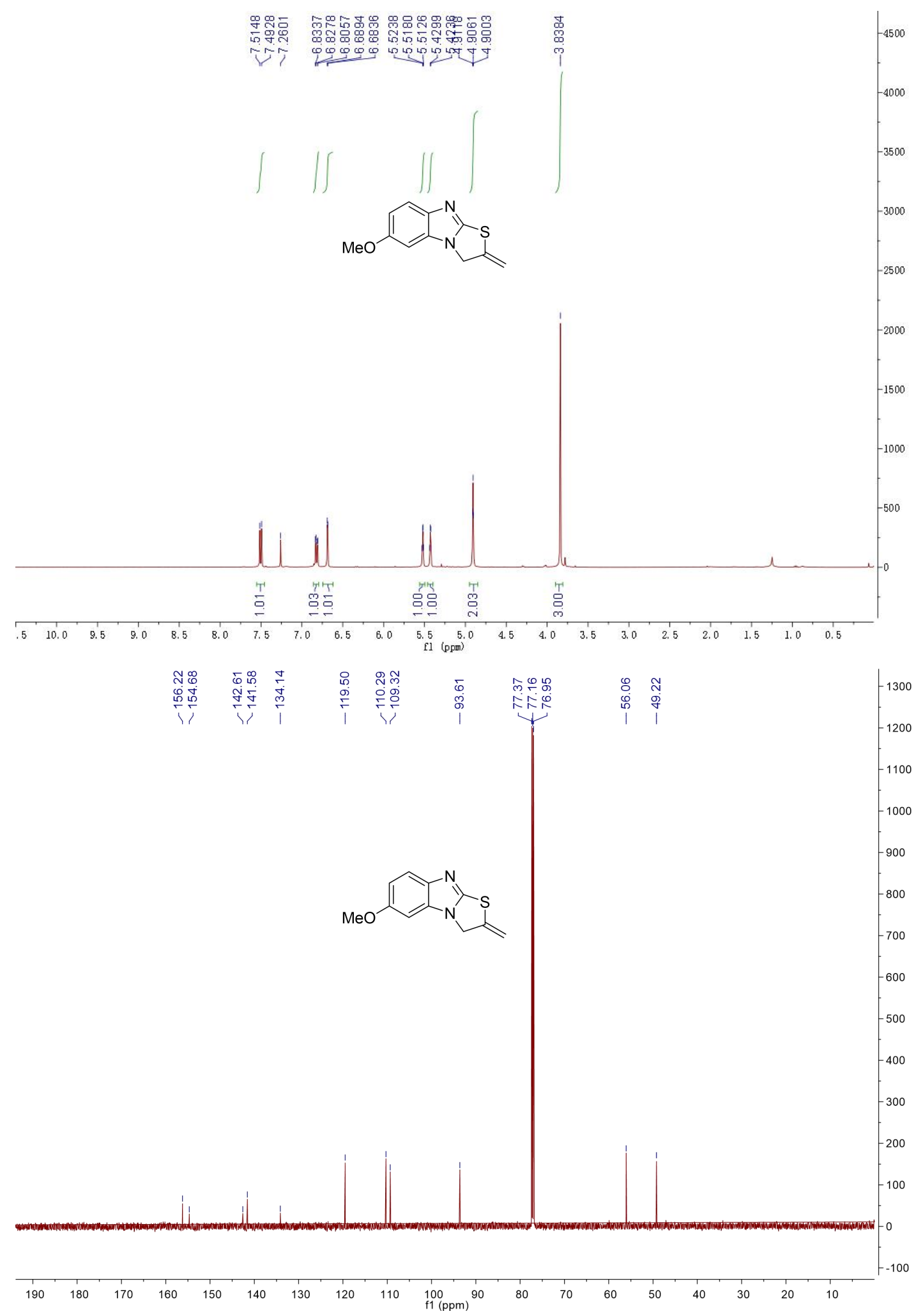


3j:
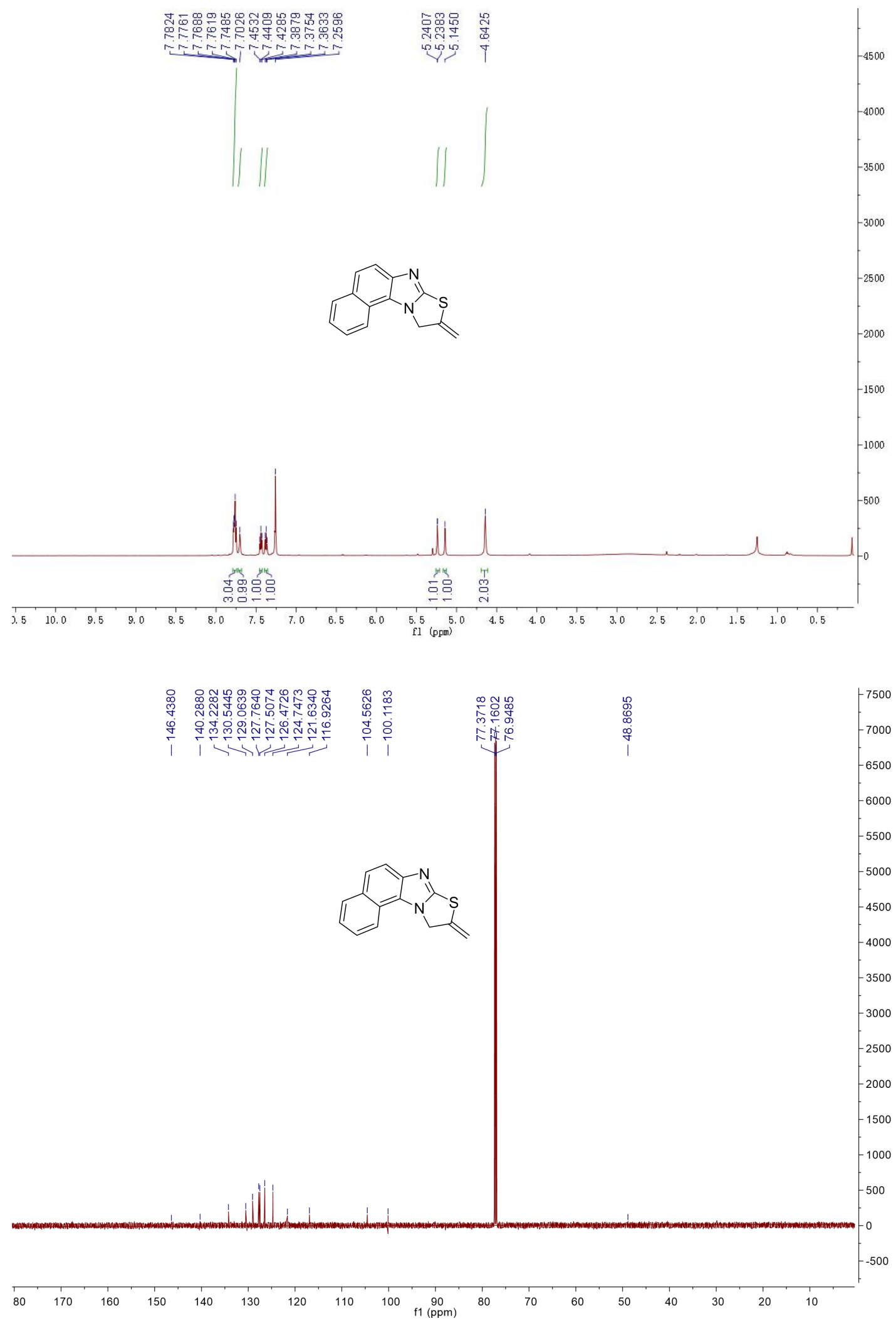
3k:

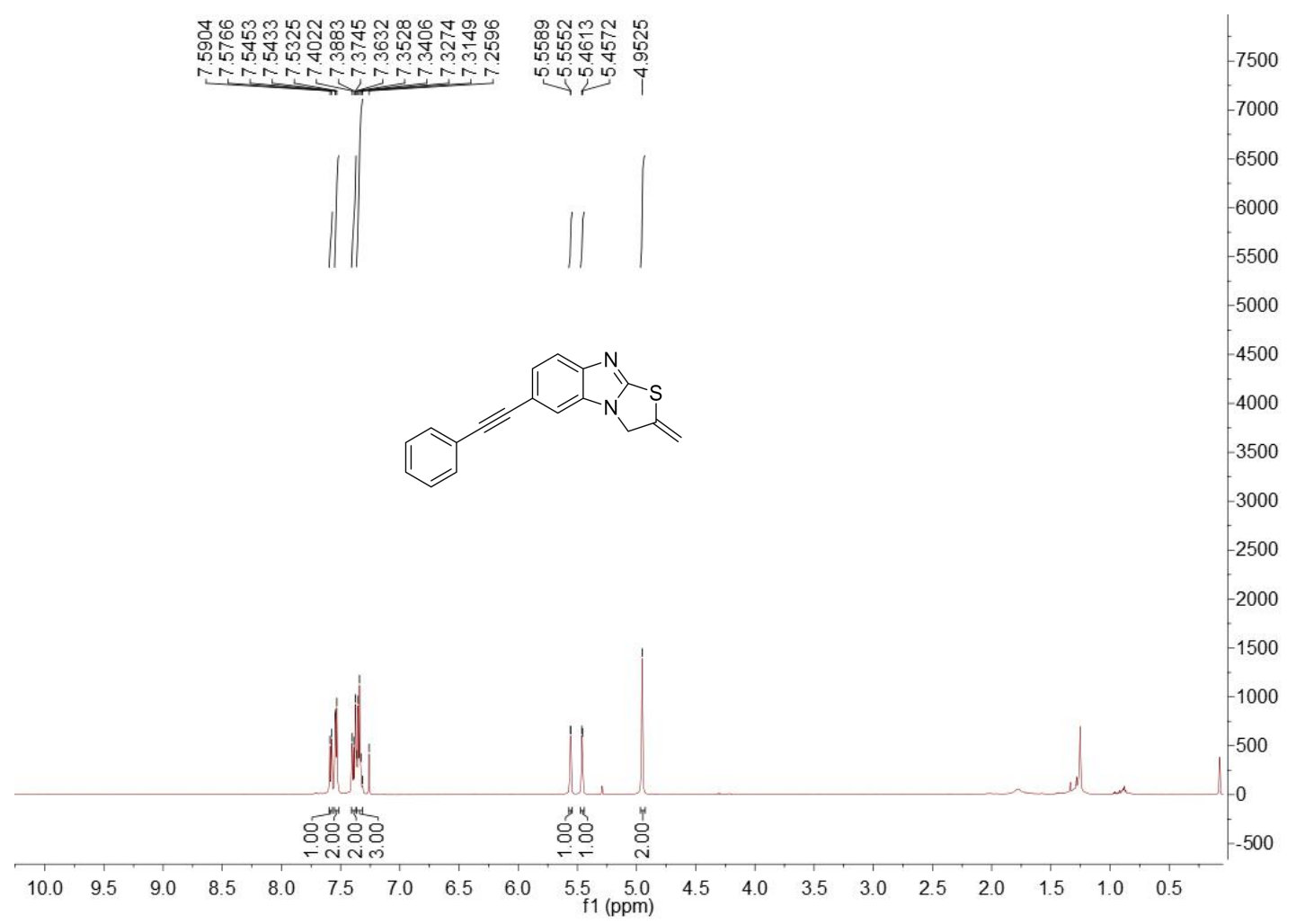

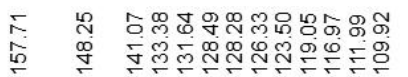

\section{๓๐ \\ 品 NN}

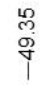

1600

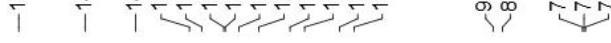

1500

$-1400$

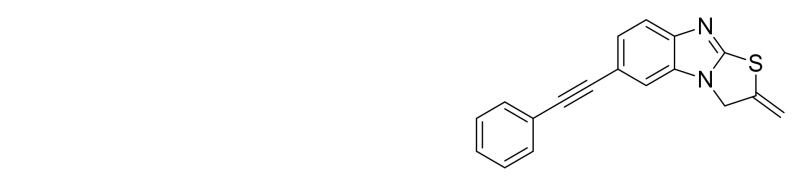

1100

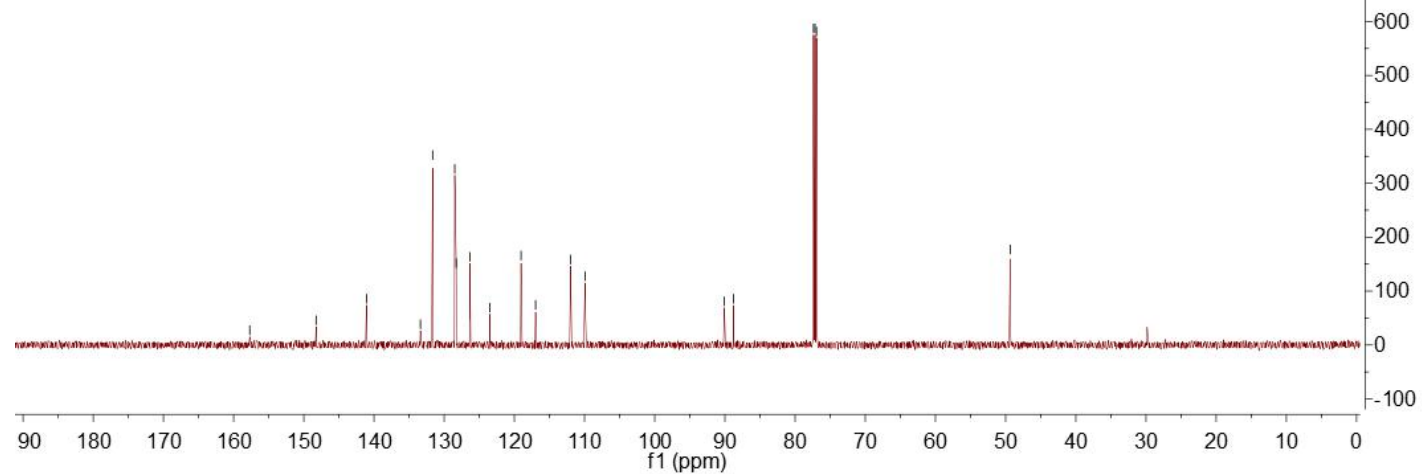


31:

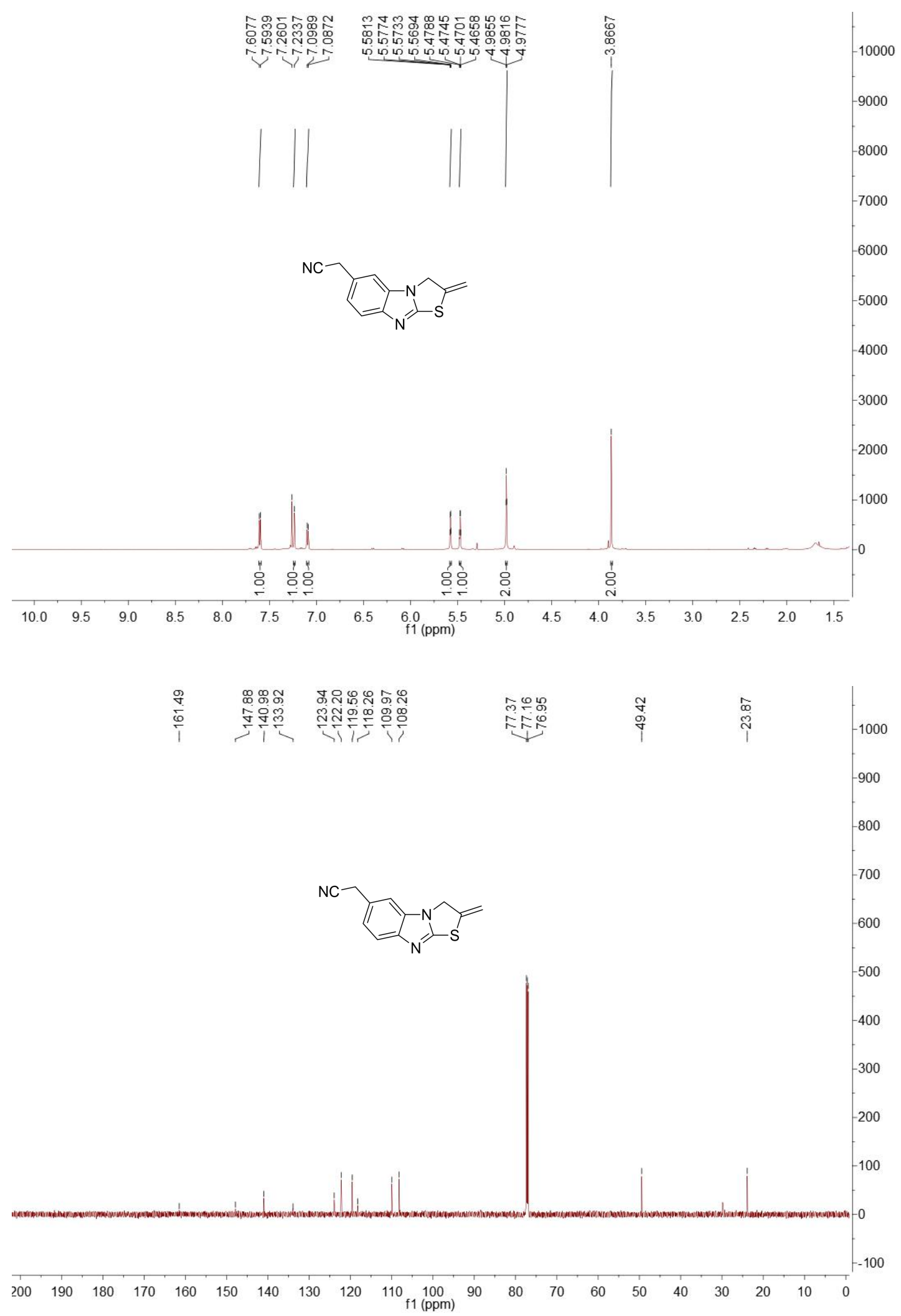


3m+3m':

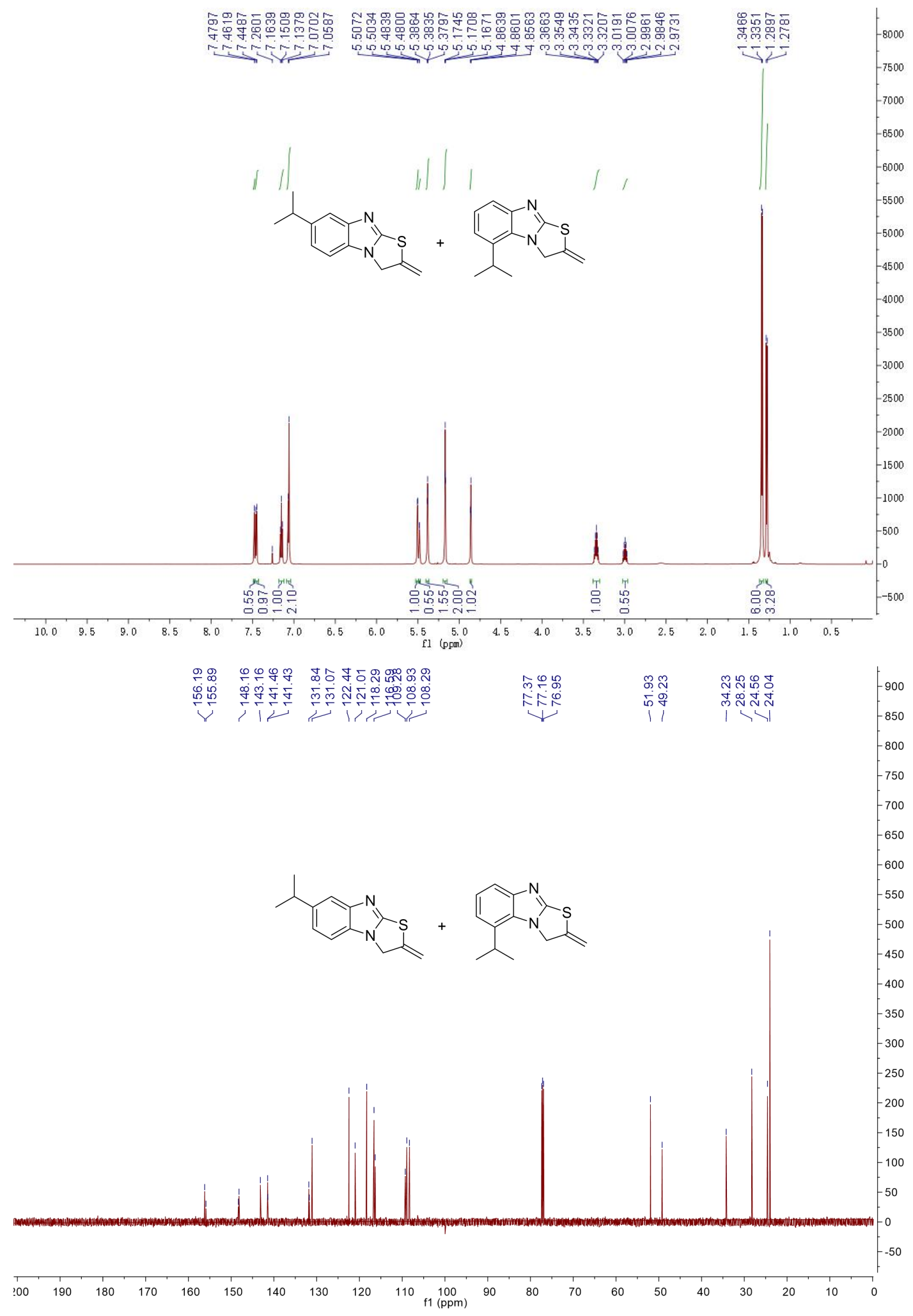


3n:
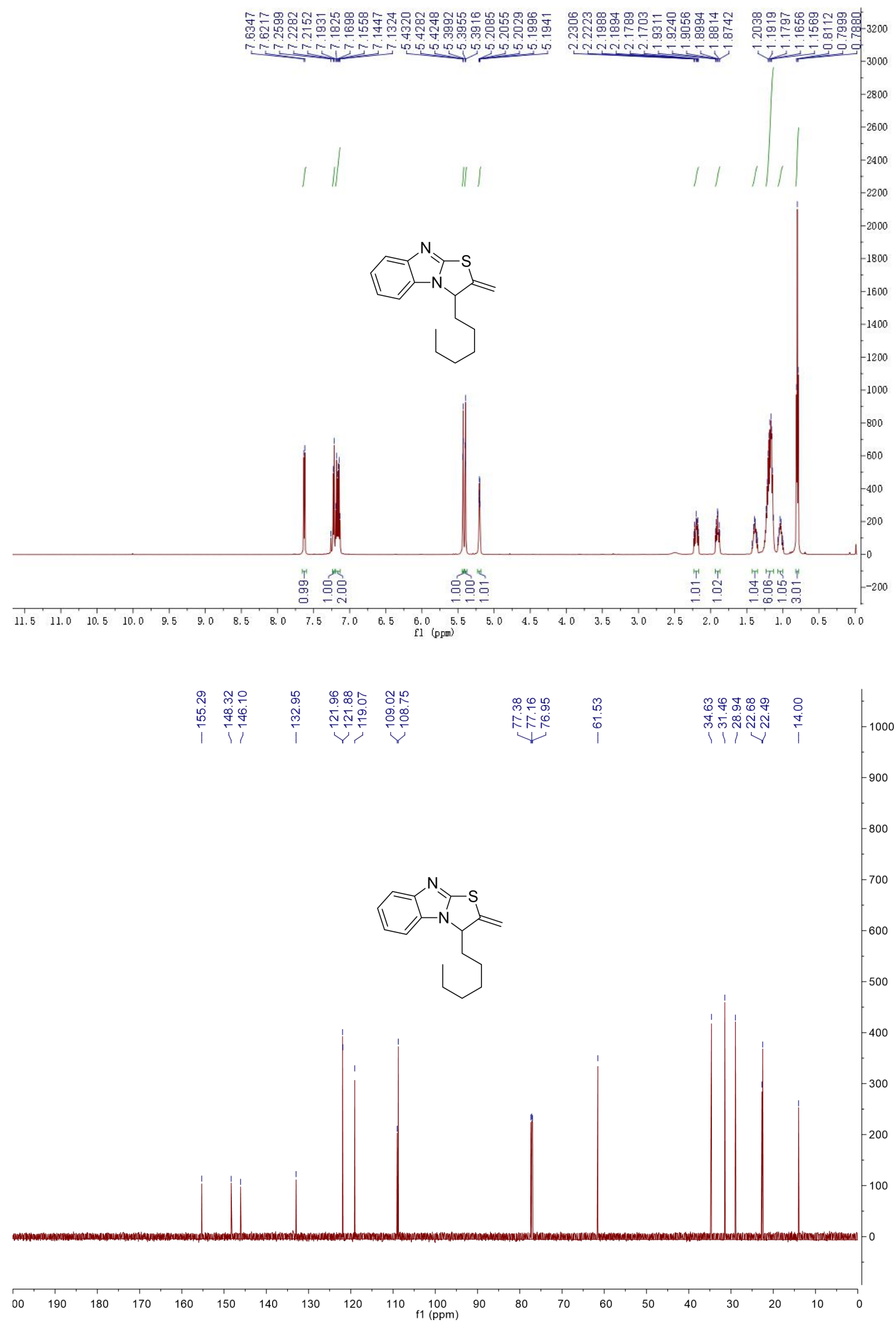
3o:
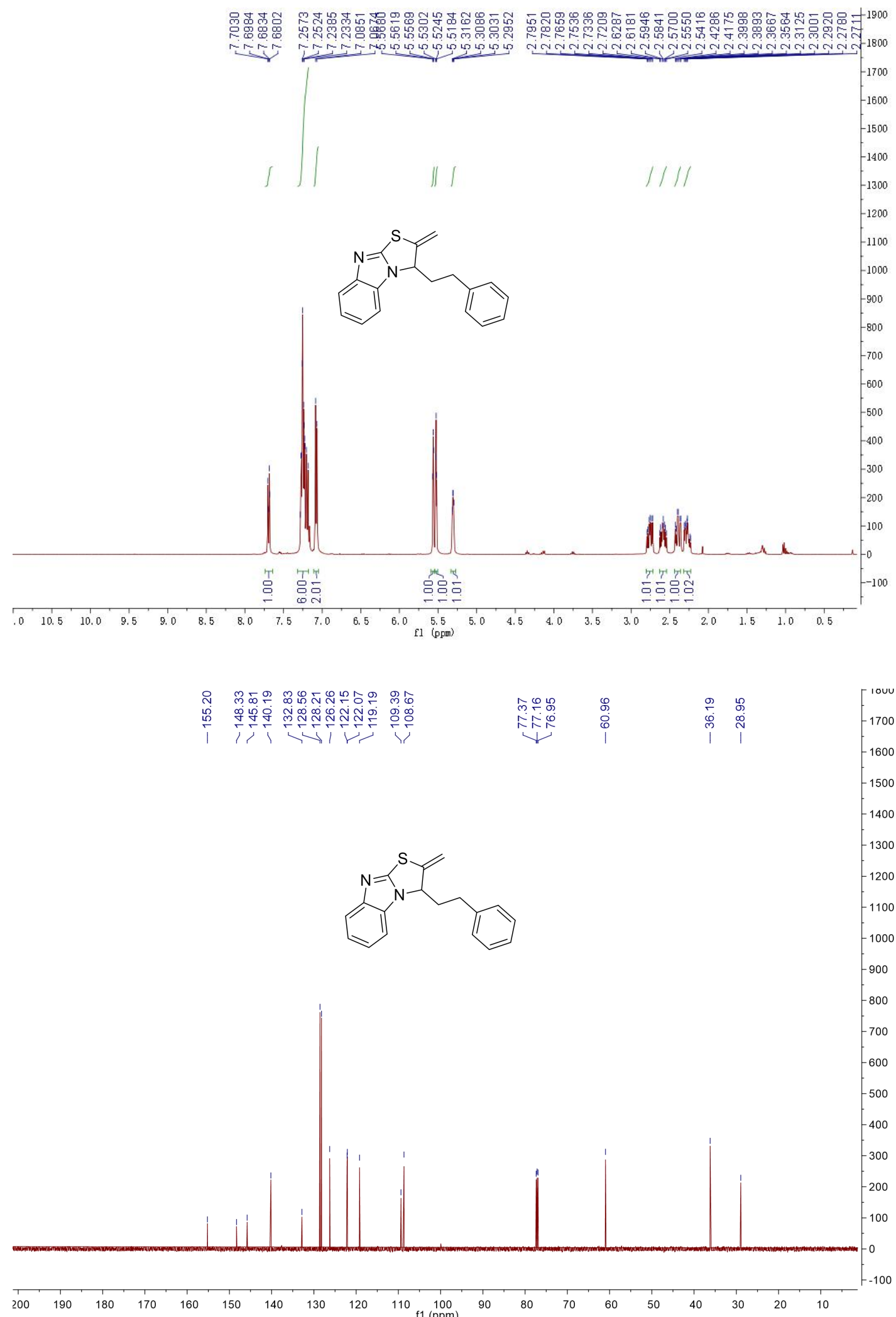
3p:
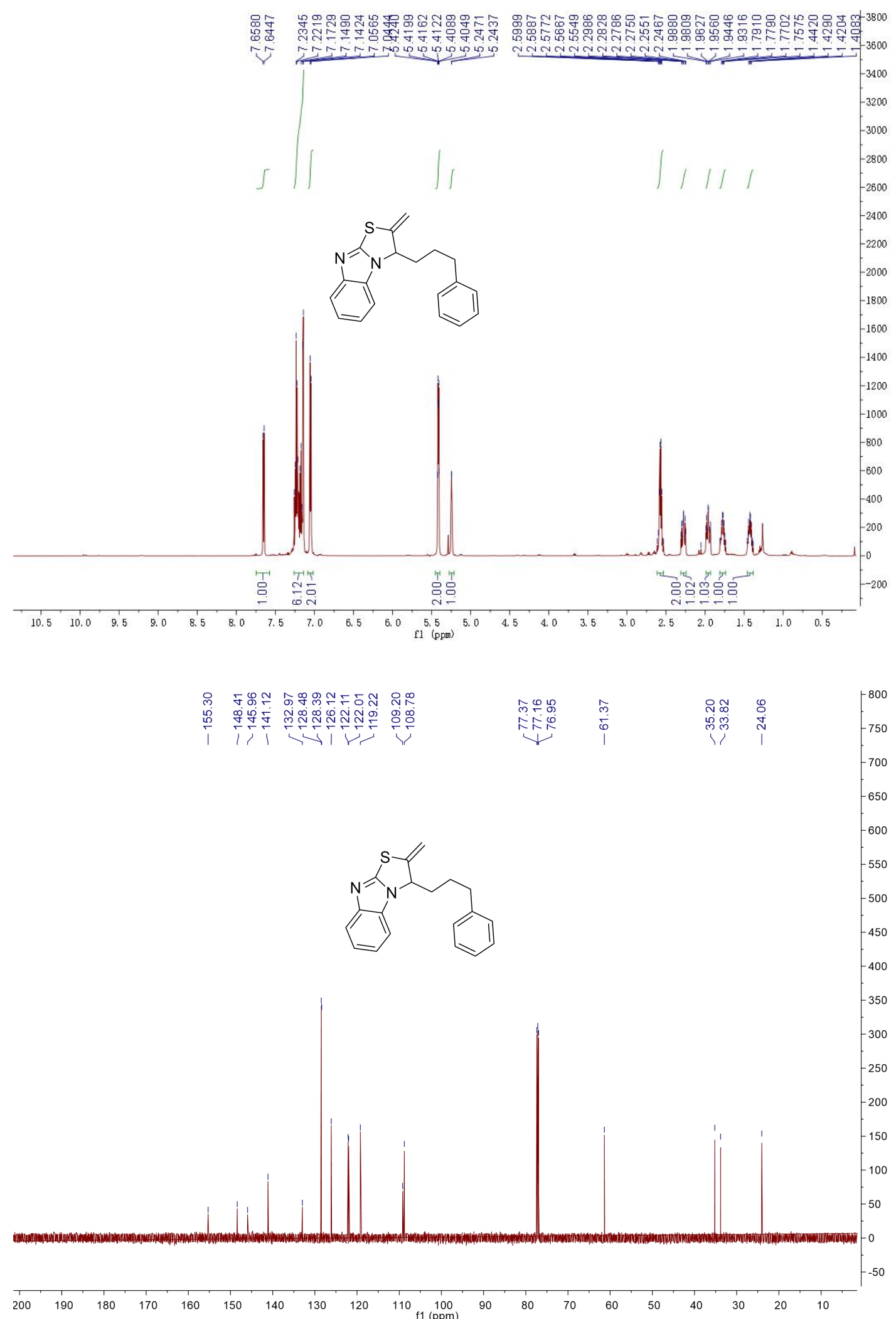
3q:

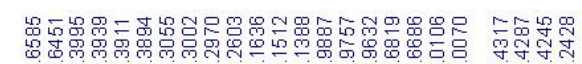

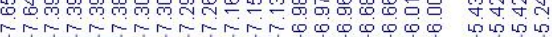
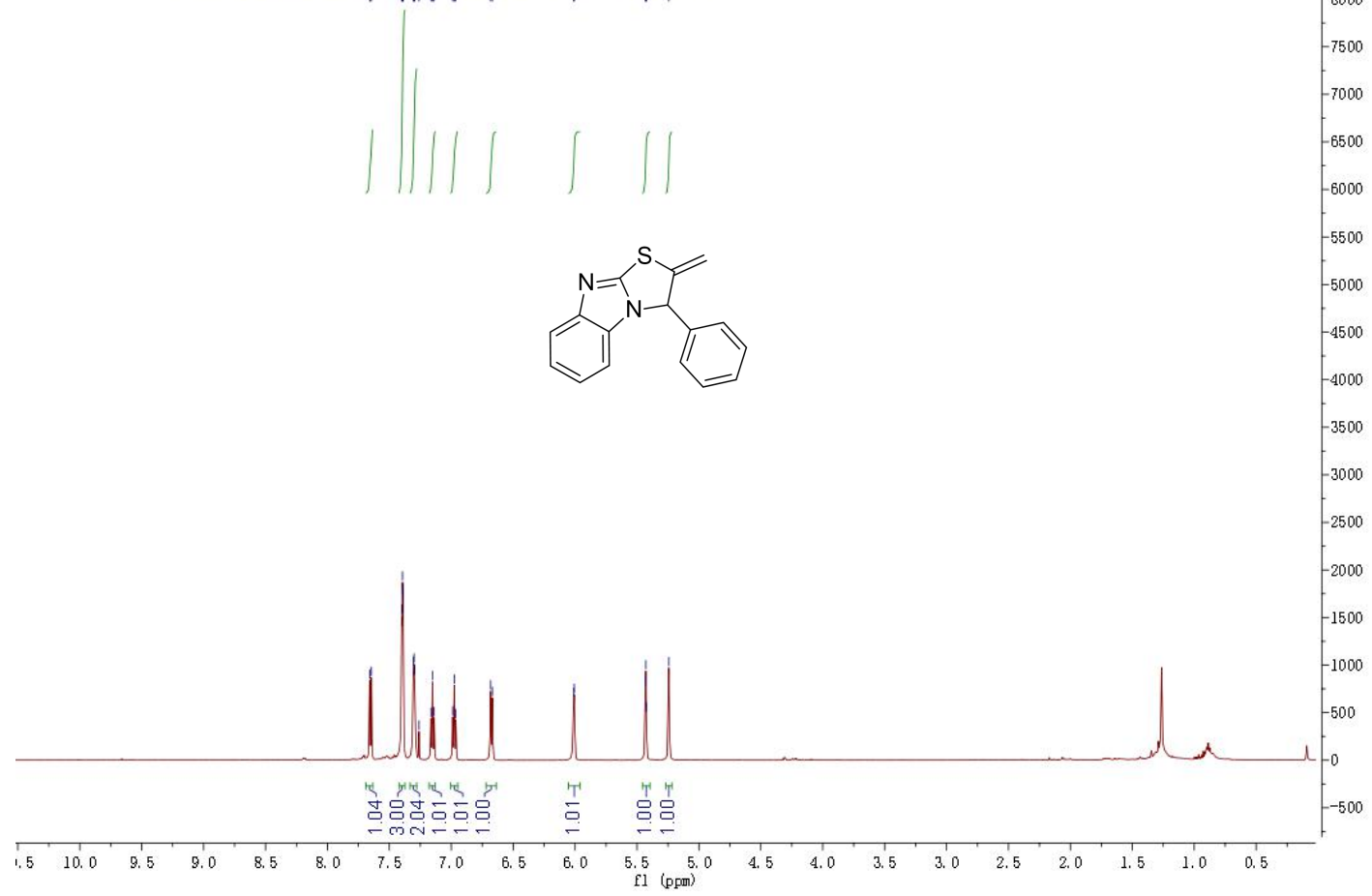

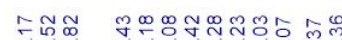

นึ๊

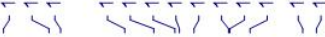

กิำำ 웅

年
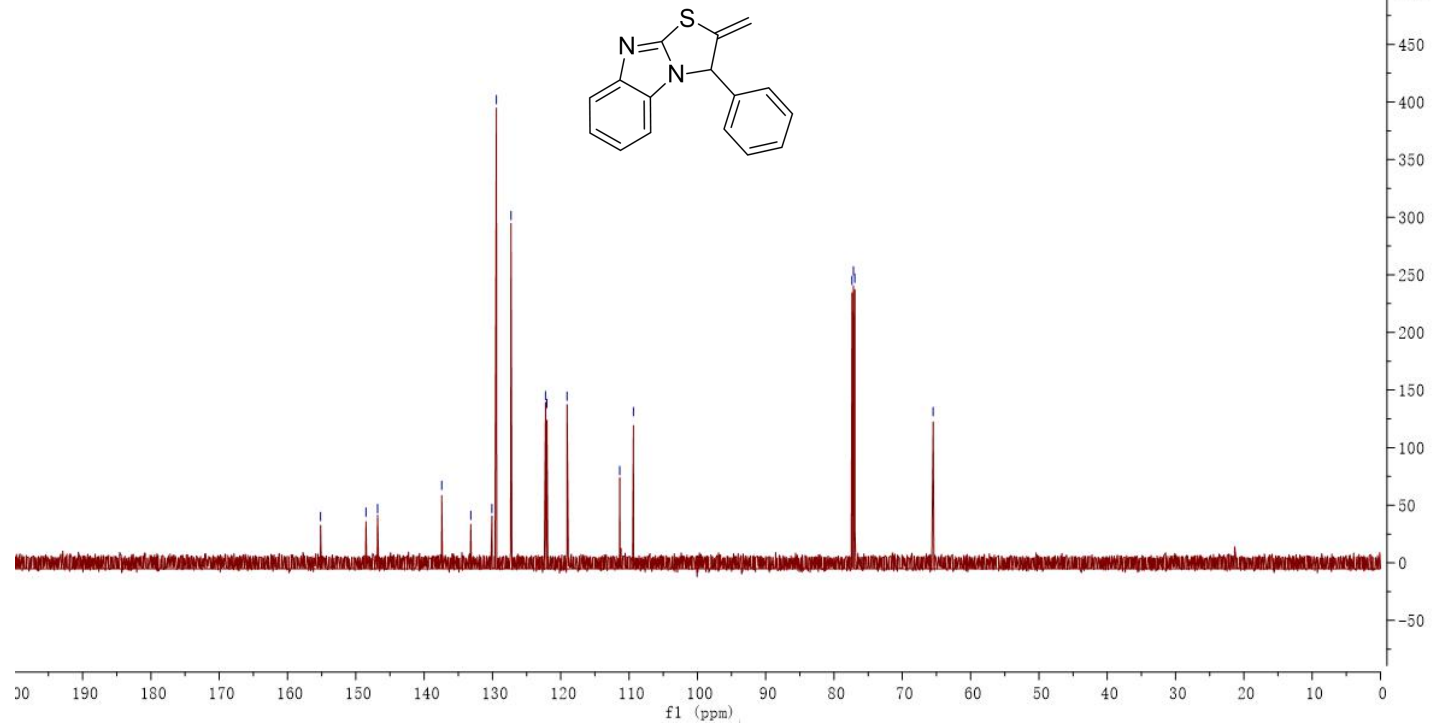
3r:
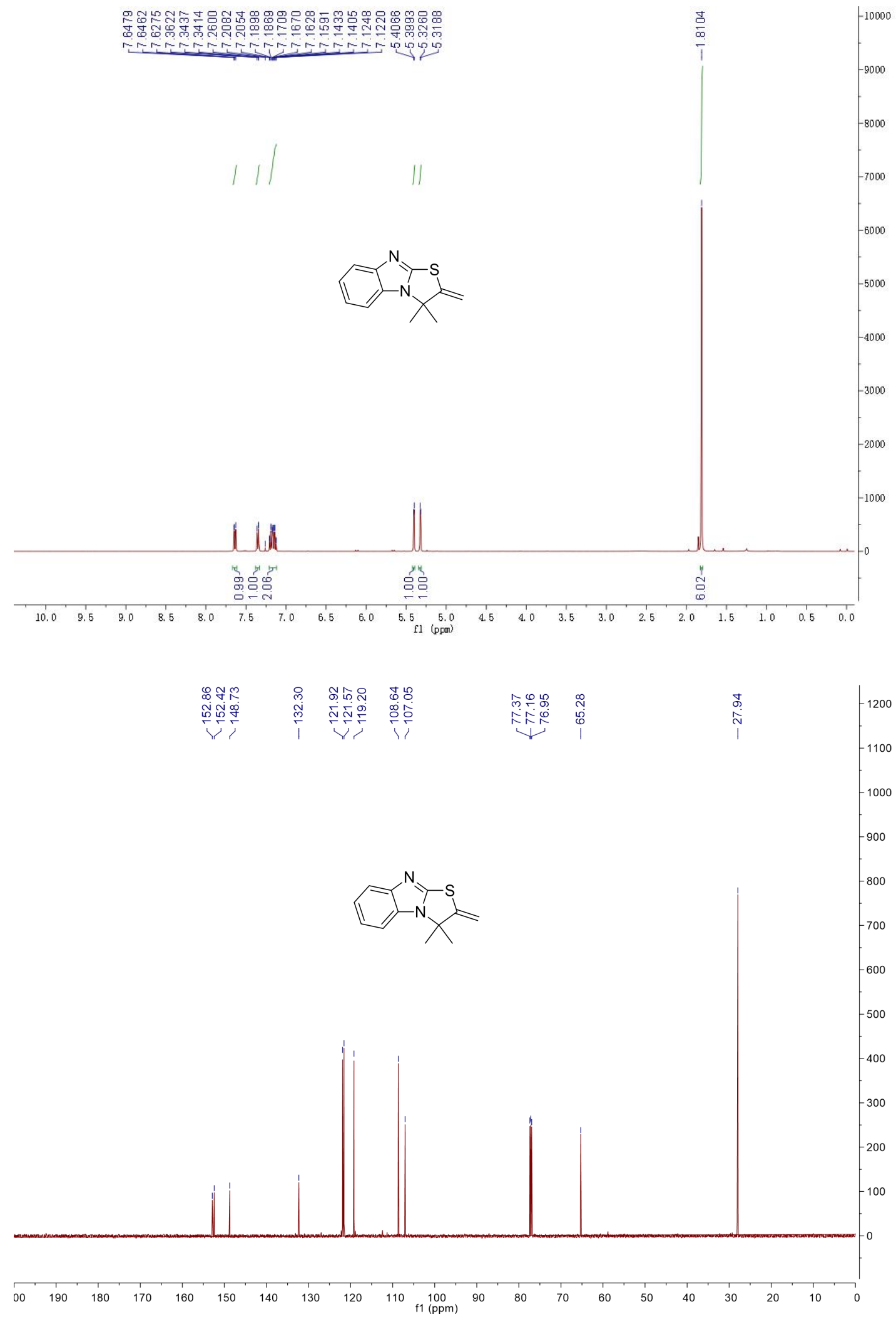
3s:

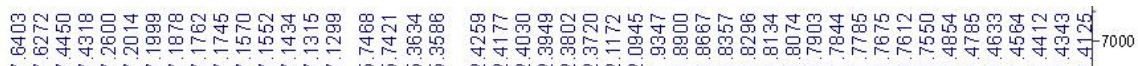

- 1500

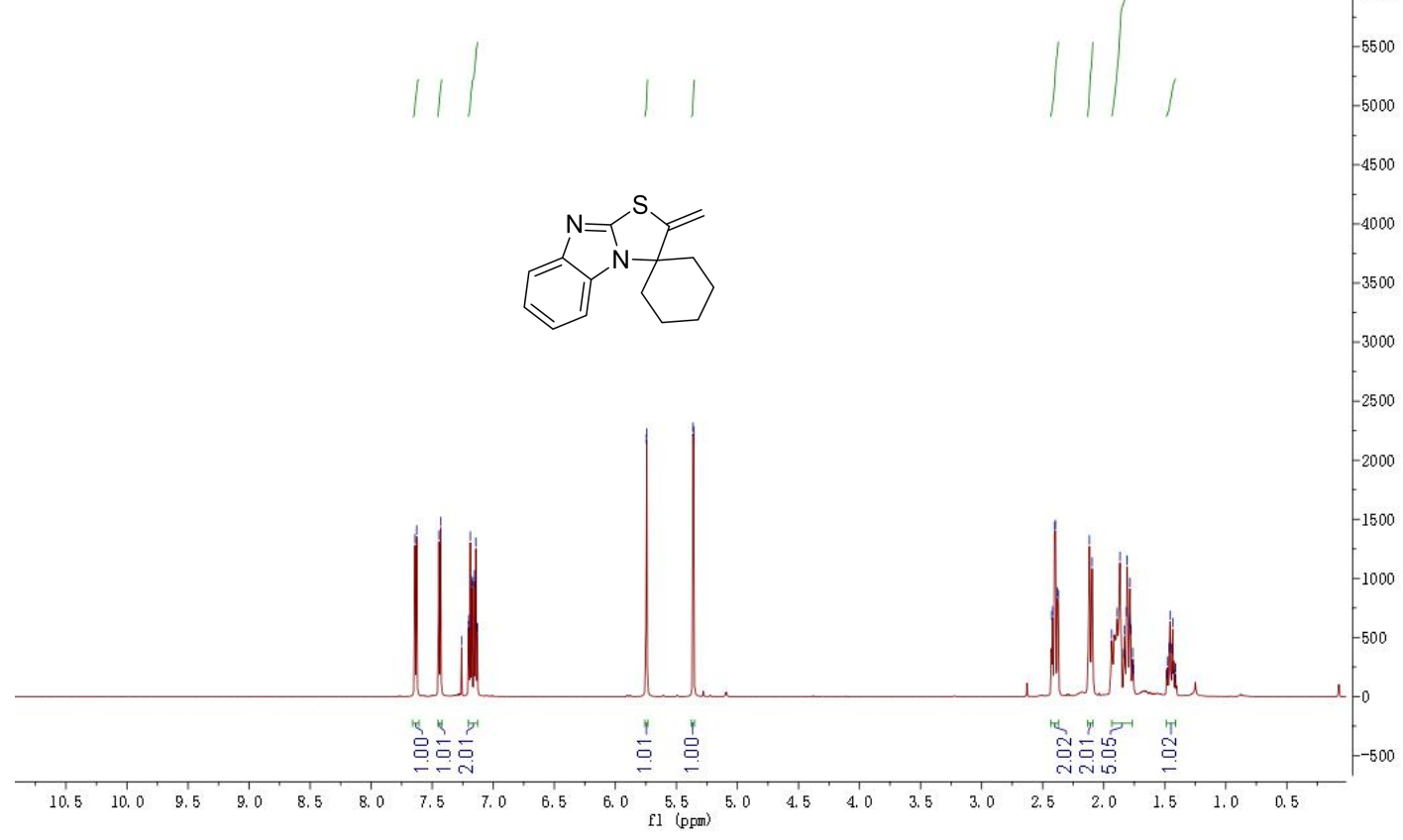

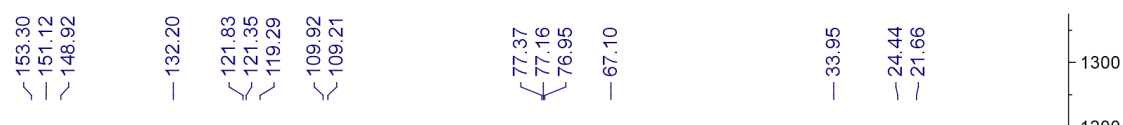
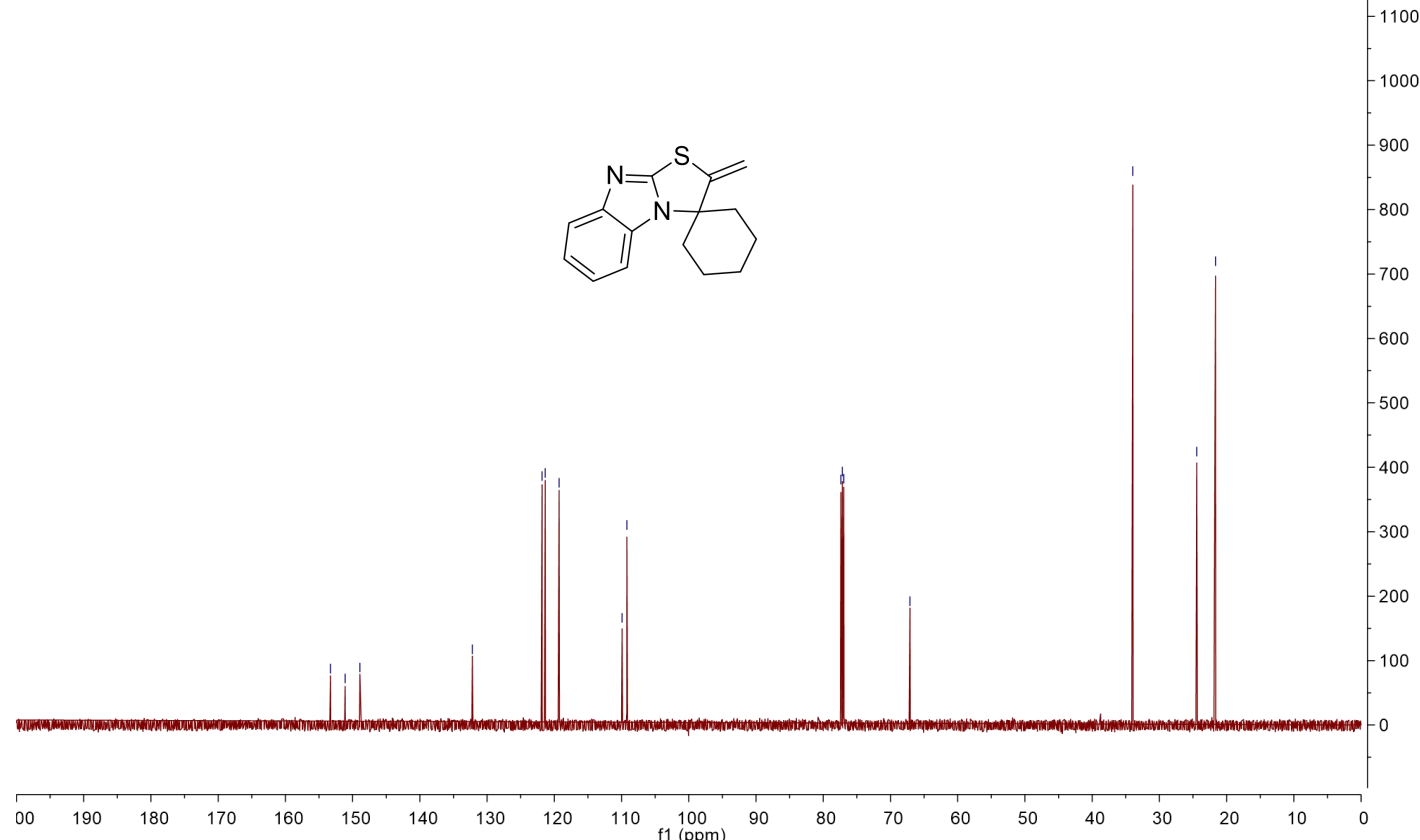
3t:

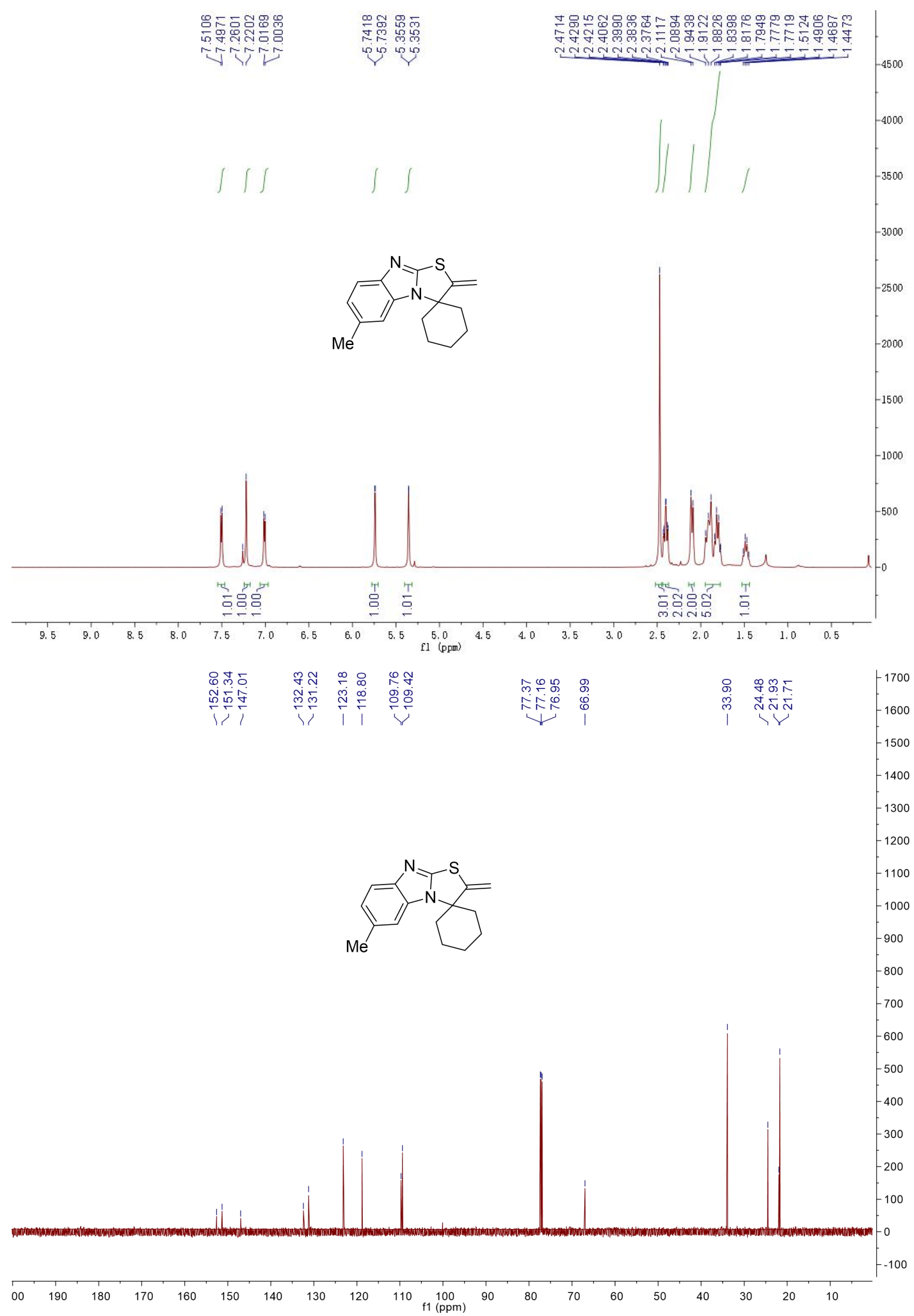


3u:
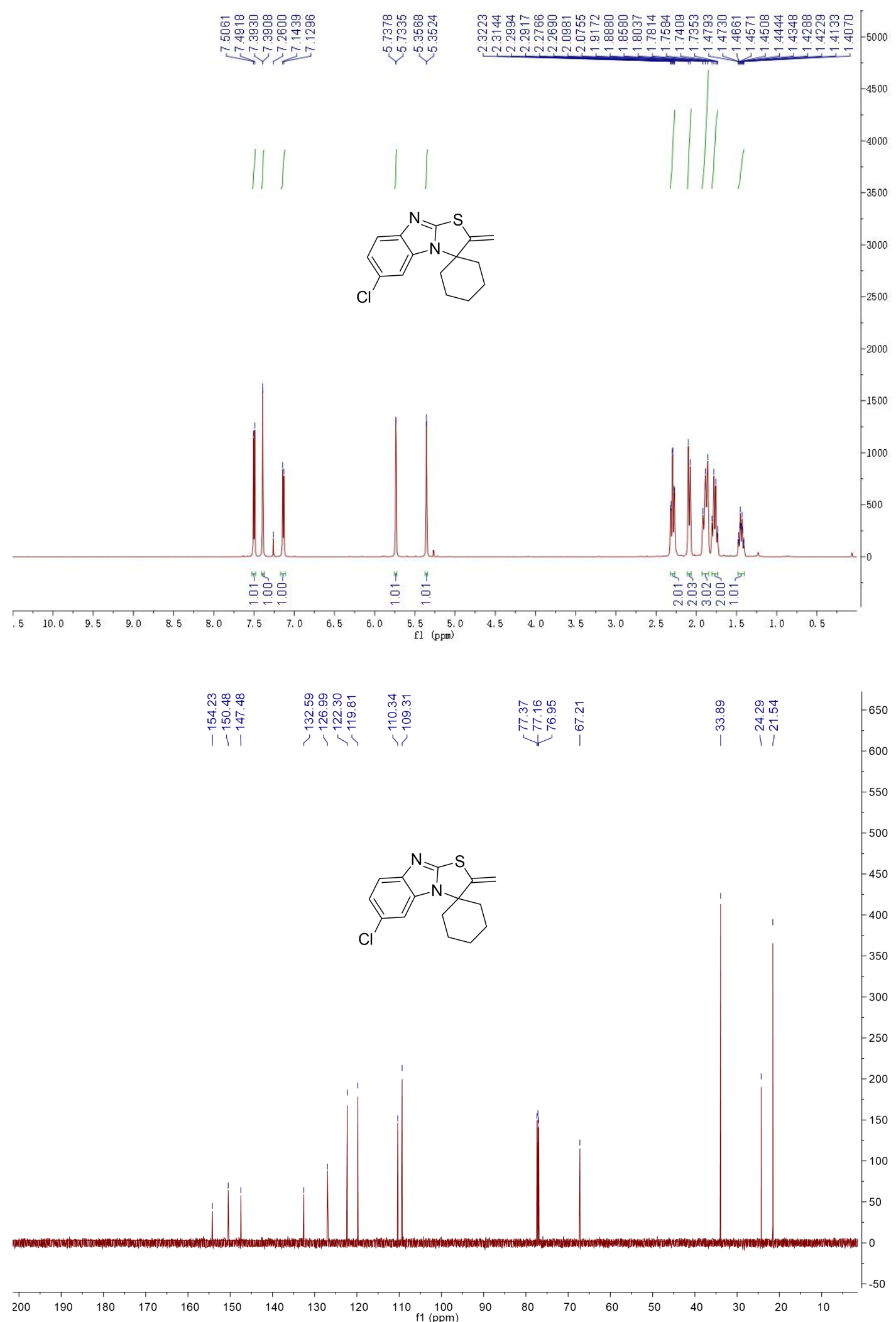


\section{3v:}

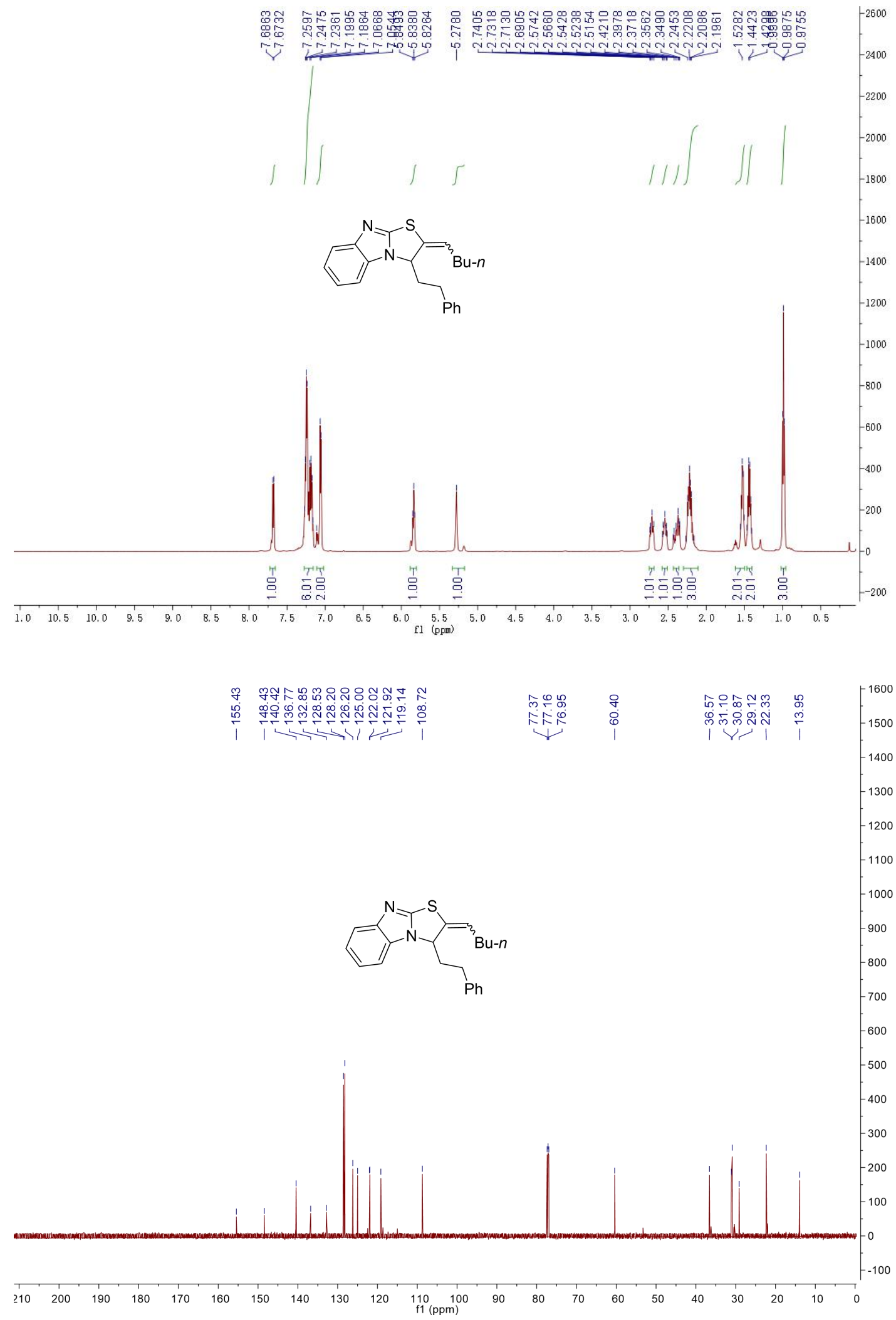


3w:
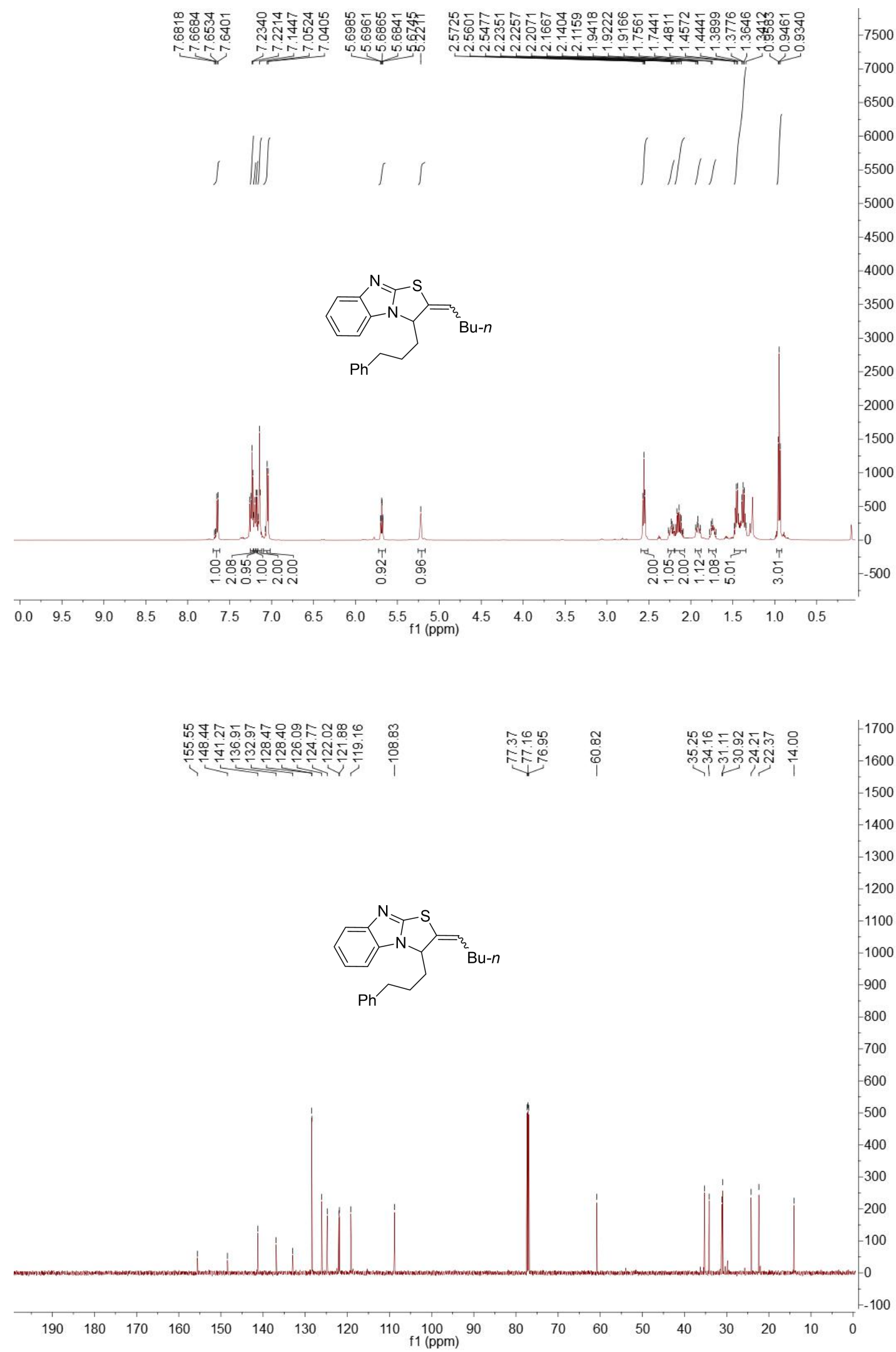
3x:

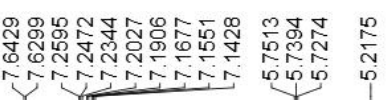

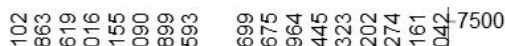

거숭

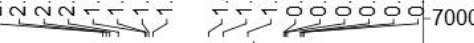

6500
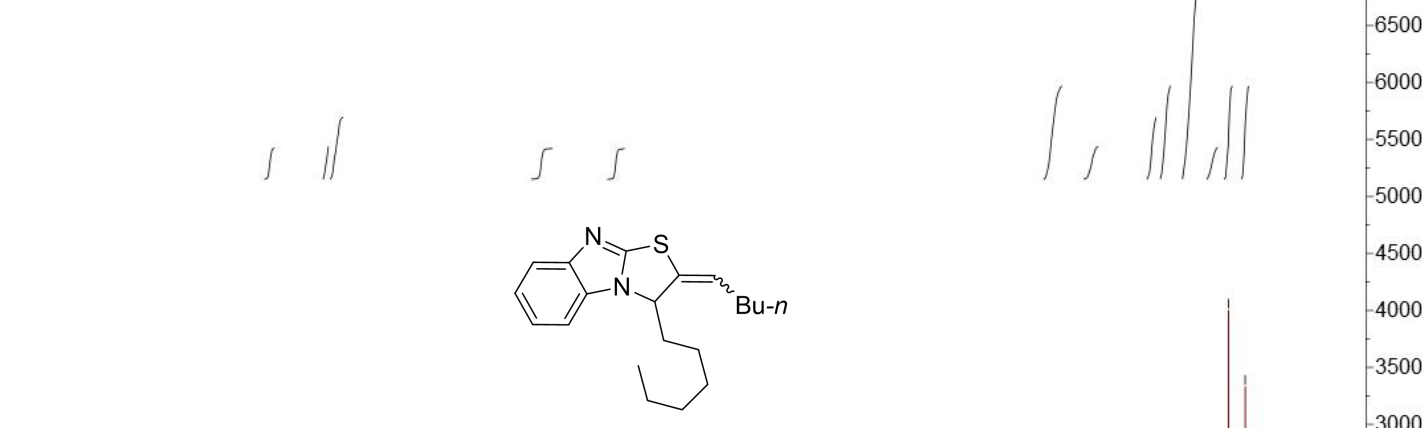

5000

4500

4000

3500

$-3000$

2500

$-2000$

$-1500$

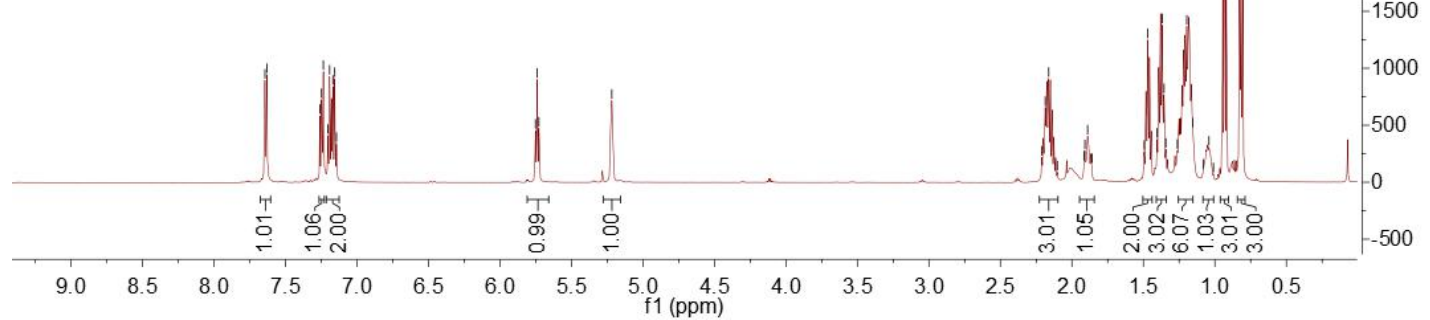

†

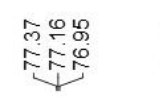

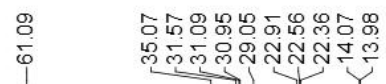

$-2600$

$-2400$

2200

2000

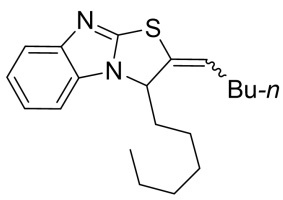

1800

600

1400

1200

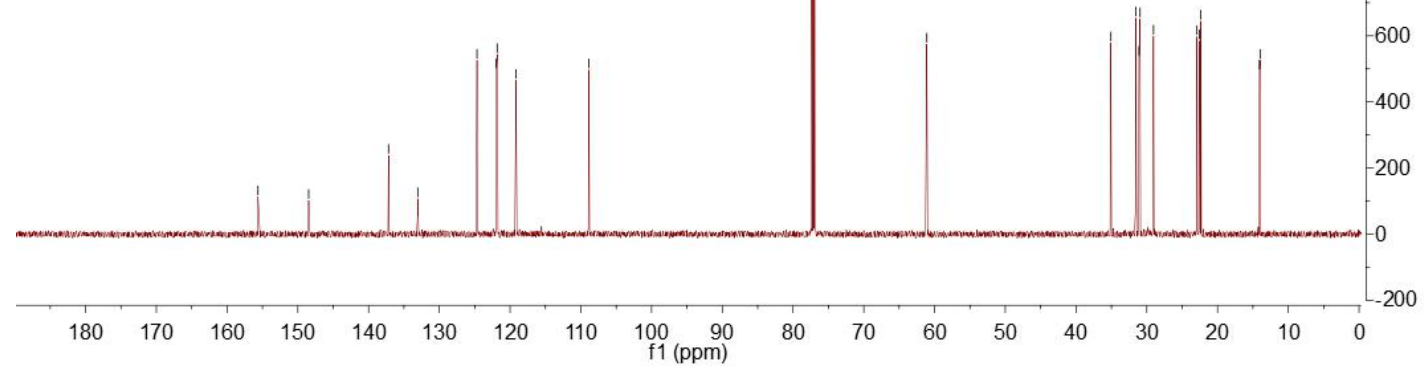


2. Copies of ${ }^{1} \mathrm{H}$ and ${ }^{13} \mathrm{C}$ NMR Spectra for Intermediate 5a

5a:
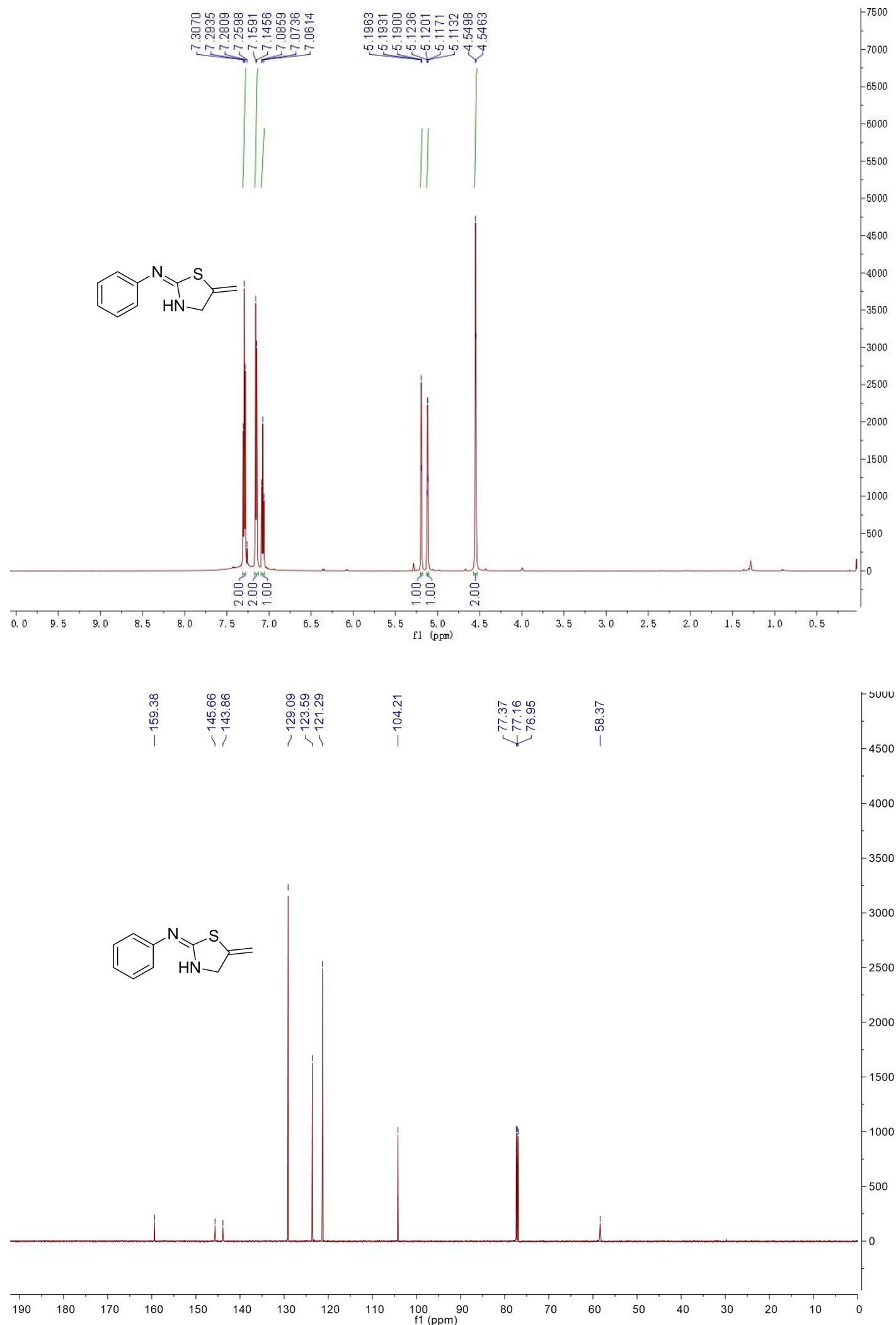


\section{Copies of ${ }^{1} \mathrm{H}$ and ${ }^{13} \mathrm{C}$ NMR Spectra for Derivative $6 a$}

6a:

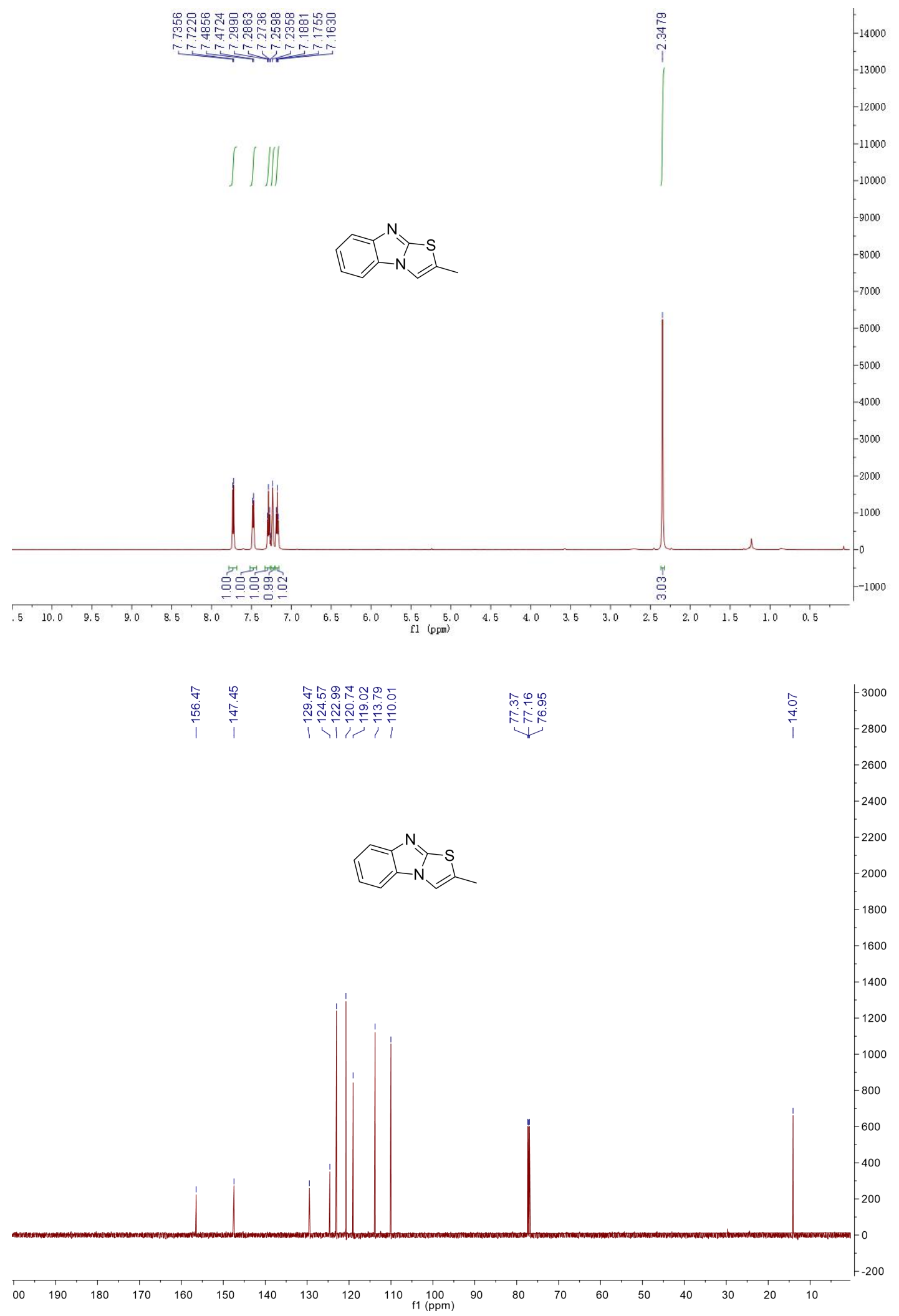




\section{Copies of ${ }^{1} \mathrm{H}$ and ${ }^{13} \mathrm{C}$ NMR Spectra for Derivatives 7}

7a:
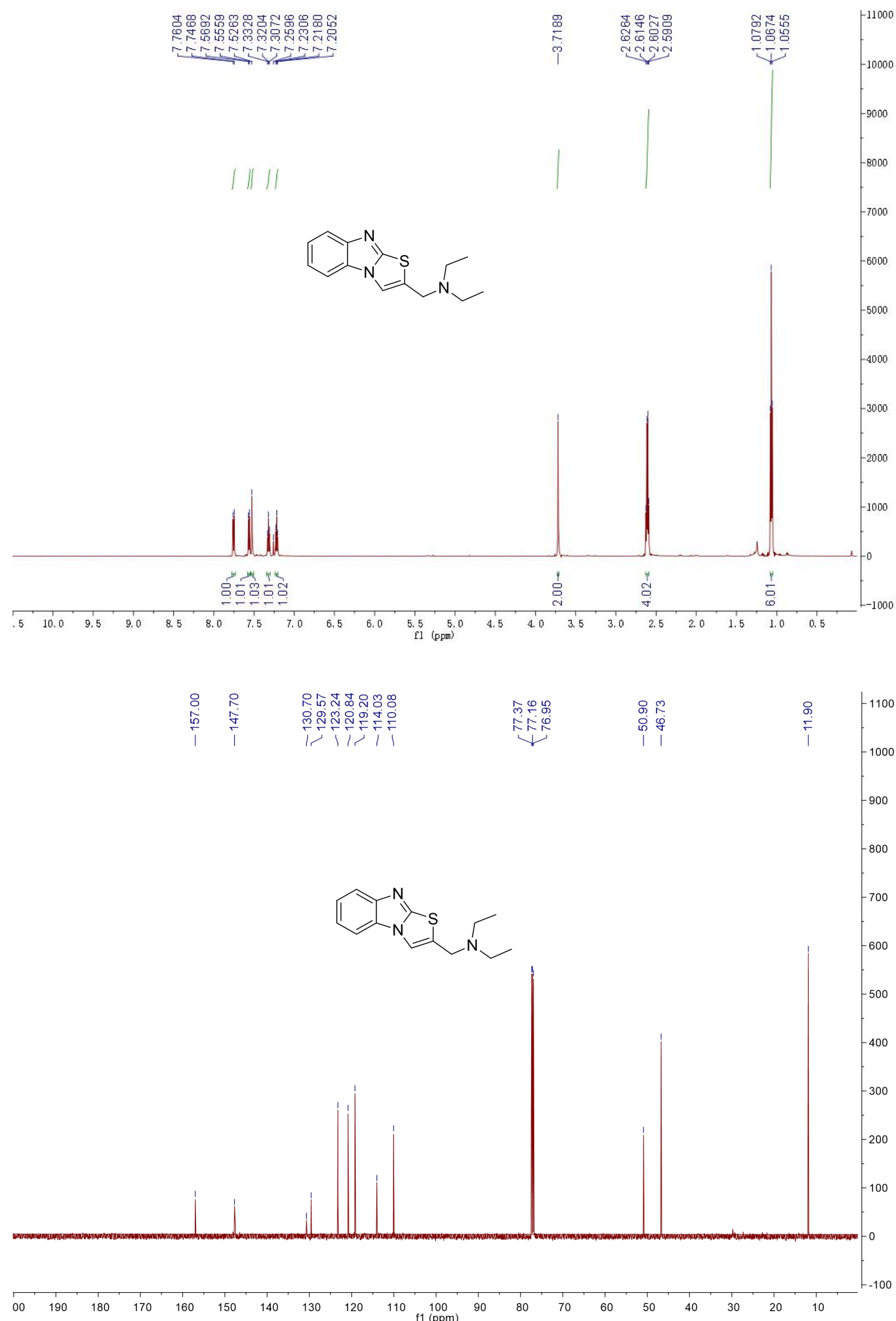
7b:
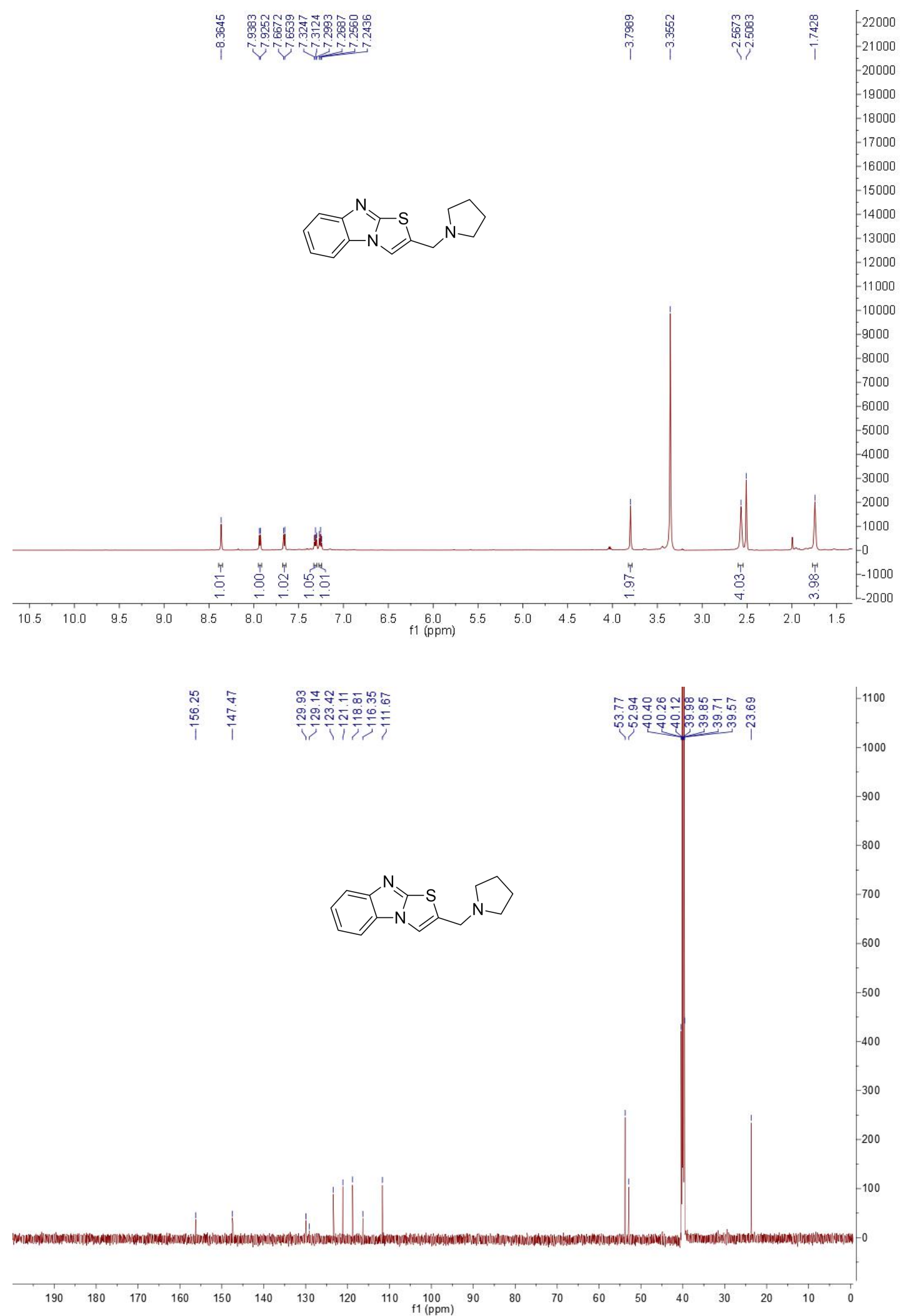
7c:

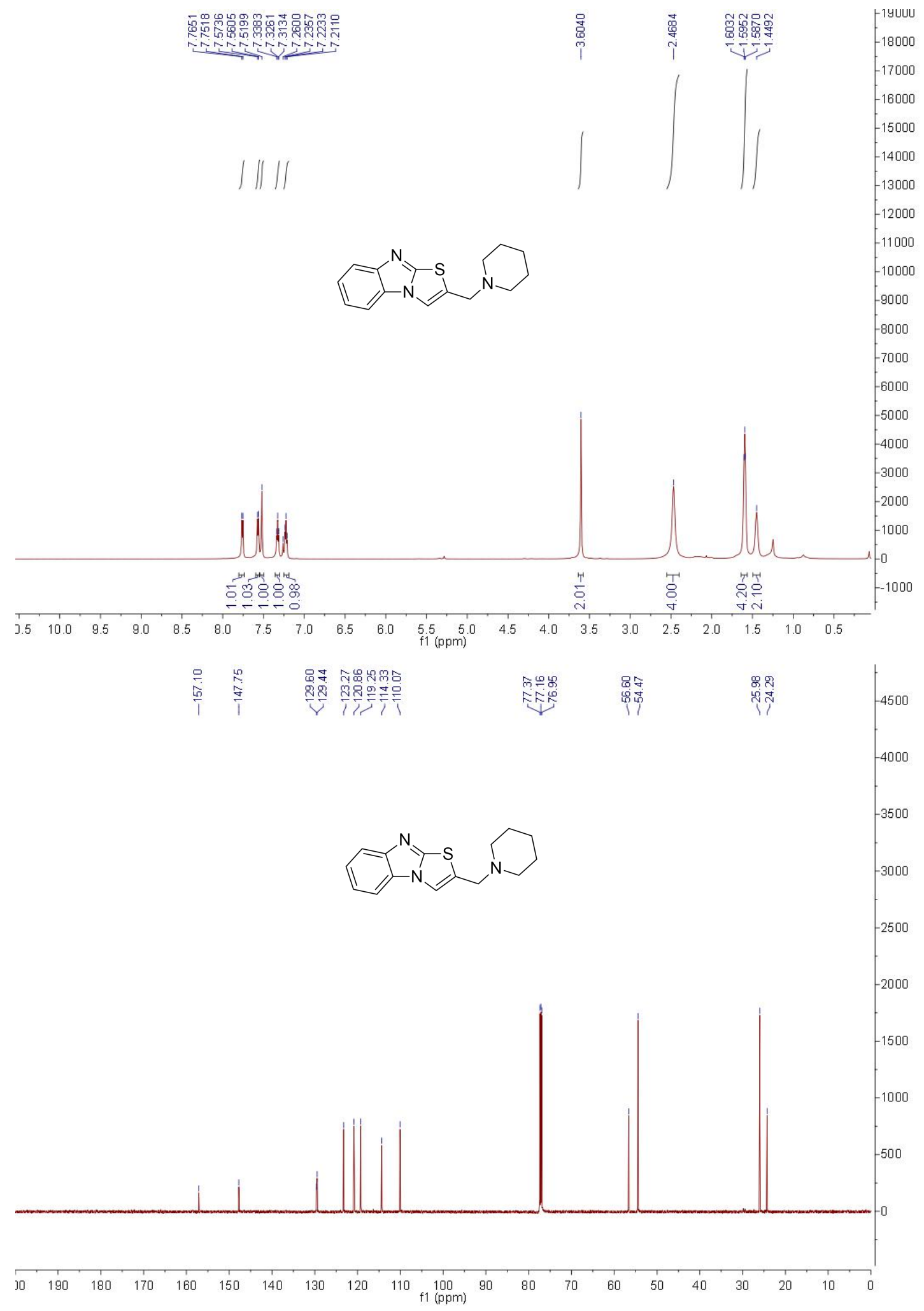




\section{Copies of ${ }^{1} \mathrm{H}$ and ${ }^{13} \mathrm{C}$ NMR Spectra for Derivative 8a}

8a:

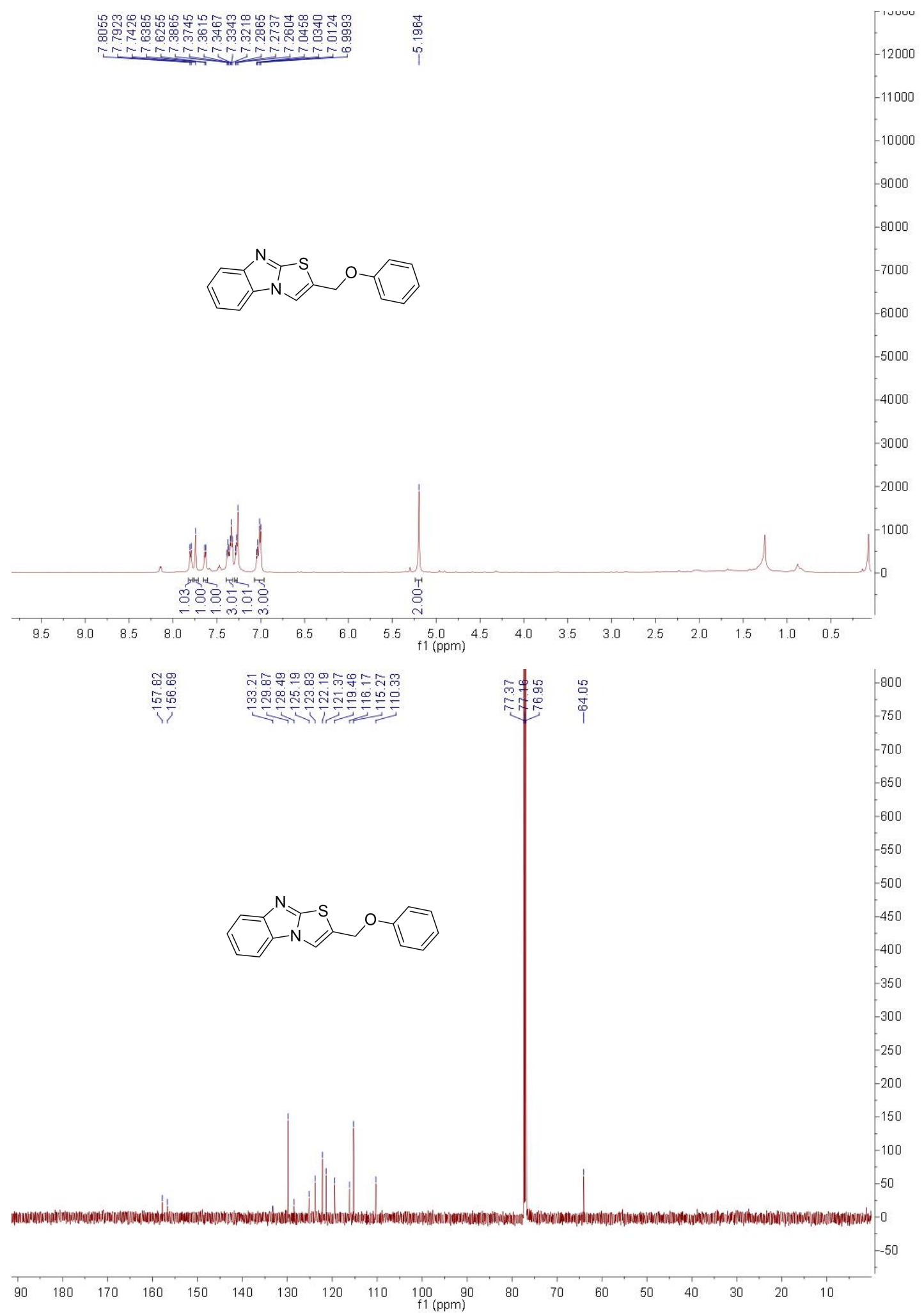




\section{The X-Ray Crystallographic Information of 3a}

\subsection{Sample Preparation.}

A solution of product $3 \mathbf{a}(0.1 \mathrm{mmol})$ in EtOAc $(2 \mathrm{~mL})$ was placed in a vial $(10 \mathrm{~mL}) . n$-Hexane $(5$ $\mathrm{mL}$ ) was added to the solution. The colorless crystals suitable for X-ray diffraction were obtained by slowly evaporating mixed solvent at room temperature under air conditions.

\subsection{Crystal Measurement.}

X-Ray crystal structure of product 3a was determined at $279 \mathrm{~K}\left(5.85^{\circ} \mathrm{C}\right)$. Thermal ellipsoids were drawn at 50\% probability level.

\subsection{X-Ray Crystallographic of Product 3a.}

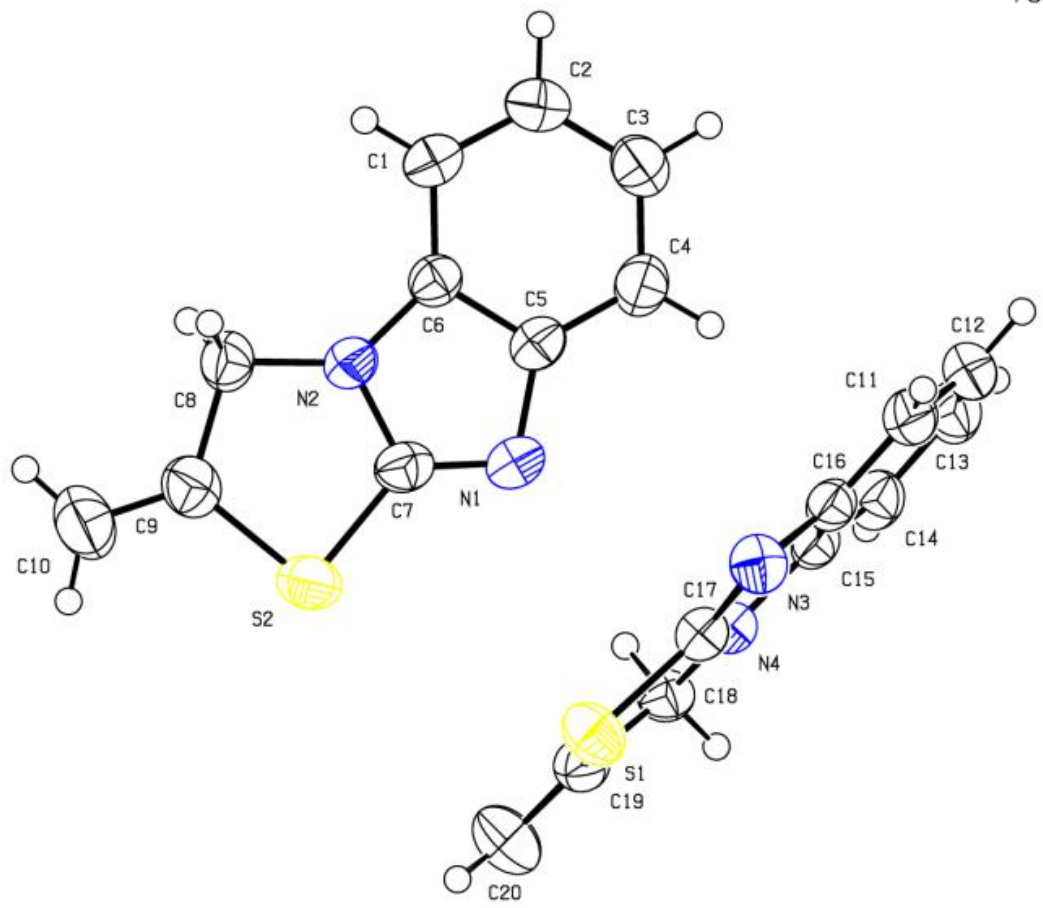

$\begin{aligned} \text { Prob } & =50 \\ \text { Temp } & =279\end{aligned}$

Figure S1. ORTEP Diagram of 3a with Ellipsoids at 50\% Probability Level 
6.4 Important Crystal Data of Product 3a.

\begin{tabular}{|c|c|c|c|}
\hline \multirow{3}{*}{$\begin{array}{l}\text { Bond precision: } \\
\text { Cell: }\end{array}$} & \multirow{2}{*}{$\begin{array}{l}\mathrm{C}-\mathrm{C}=0.0021 \mathrm{~A} \\
\mathrm{a}=9.2794(5)\end{array}$} & \multicolumn{2}{|c|}{ Wavelength $=0.71073$} \\
\hline & & $\mathrm{b}=9.3445(5)$ & $\mathrm{c}=10.3560(4)$ \\
\hline & alpha $=89.2189(18)$ & beta $=89.7152(19)$ & gamma $=82.646(2)$ \\
\hline \multirow[t]{2}{*}{ Temperature: } & $279(2) \mathrm{K}$ & & \\
\hline & Calculated & Reported & \\
\hline Volume & $890.51(8)$ & $890.51(8)$ & \\
\hline Space group & $\mathrm{P}-1$ & $\mathrm{P}-1$ & \\
\hline Hall group & $-\mathrm{P} 1$ & $-\mathrm{P} 1$ & \\
\hline Moiety formula & $\mathrm{C}_{10} \mathrm{H}_{8} \mathrm{~N}_{2} \mathrm{~S}$ & $\mathrm{C}_{10} \mathrm{H}_{8} \mathrm{~N}_{2} \mathrm{~S}$ & \\
\hline Sum formula & $\mathrm{C}_{10} \mathrm{H}_{8} \mathrm{~N}_{2} \mathrm{~S}$ & $\mathrm{C}_{10} \mathrm{H}_{8} \mathrm{~N}_{2} \mathrm{~S}$ & \\
\hline $\mathrm{Mr}$ & 188.24 & 188.24 & \\
\hline Dx, $\mathrm{g} \mathrm{cm}^{-3}$ & 1.404 & 1.404 & \\
\hline Z & 4 & 4 & \\
\hline $\mathrm{Mu}\left(\mathrm{mm}^{-1}\right)$ & 0.310 & 0.310 & \\
\hline F000 & 392.0 & 392.0 & \\
\hline F000' & 392.60 & & \\
\hline $\mathrm{h}, \mathrm{k}, \mathrm{l}_{\max }$ & $12,12,13$ & $12,12,13$ & \\
\hline $\mathrm{N}_{\text {ref }}$ & 4061 & 3932 & \\
\hline $\mathrm{T}_{\min }, \mathrm{T}_{\max }$ & $0.833,0.897$ & & \\
\hline $\mathrm{T}_{\min }$ & 0.833 & & \\
\hline \multicolumn{4}{|c|}{ Correction method $=$ Not given } \\
\hline \multicolumn{2}{|c|}{ Data completeness $=0.968$} & \multicolumn{2}{|c|}{$\operatorname{Theta}(\max )=27.462$} \\
\hline \multicolumn{2}{|c|}{$\mathrm{R}($ reflections $)=0.0376(3460)$} & \multicolumn{2}{|c|}{$\mathrm{wR} 2($ reflections $)=0.1081(3932)$} \\
\hline \multicolumn{2}{|l|}{$\mathrm{S}=1.018$} & $\mathrm{Npar}=235$ & \\
\hline
\end{tabular}

